\title{
Electrical Power Conditioning System for Thermoelectric Waste Heat Recovery in Commercial Vehicles
}

\author{
Arash Edvin Risseh, Student Member, IEEE, Hans-Peter Nee, Fellow, IEEE, and Christophe \\ Goupil, Member, IEEE
}

\begin{abstract}
A considerable part of the fuel energy in vehicles never reaches the wheels and entirely converts to waste heat. In a heavy duty vehicle (HDV) the heat power that escapes from the exhaust system may reach $170 \mathrm{~kW}$. The waste heat can be converted into useful electrical power using thermoelectric generator (TEG). During the last decades, many studies on the electrical power conditioning system of TEGs have been conducted. However, there is a lack of studies evaluating the electrical instrumentation, the impact of the converter-efficiency, and the TEG arrangement on a real large-scale TEG on-board a drivable vehicle. In this study, the most important parameters for designing electrical power conditioning systems for two TEGs, developed for a real-scale HDV as well as experimental results demonstrating the recovered electrical power, are presented. Eight synchronous inter-leaved step-down converters with $98 \%$ efficiency with perturb and observe maximum power point tracker was developed and tested for this purpose. The power conditioning system was communicating with the on-board computers through the controller area network and reported the status of the TEGs and the recovered electrical power. The maximum recovered electrical power from the TEGs reached $1 \mathrm{~kW}$ which was transmitted to the electrical system of the vehicle, relieving the internal combustion engine.
\end{abstract}

Index Terms-Thermoelectricity, waste heat recovery, power converter, power management, silicon carbide MOSFET, maximum power point tracker, inter-leaved converter, internal combustion engine, energy harvesting, heavy duty vehicle, thermoelectric generator, renewable energy sources, exhaust system.

\section{ABBREVIATIONS}

$\begin{array}{ll}\text { ABV } & \text { Actual battery voltage } \\ \text { ATS } & \text { After treatment system } \\ \text { CAN } & \text { Controller area network } \\ \text { ECU } & \text { Electronic control unit } \\ \text { EGR } & \text { Exhaust gas recycling system } \\ \text { emf } & \text { Electromotive force } \\ \text { EPA } & \text { Environmental protection agency } \\ \text { HDV } & \text { Heavy duty vehicle } \\ \text { HX } & \text { Heat exchanger } \\ \text { ICE } & \text { Internal combustion engine } \\ \text { LHC } & \text { Long haulage driving cycle } \\ \text { MPPT } & \text { Maximum power point tracker } \\ \text { PWM } & \text { Pulse width modulation } \\ \text { RBV } & \text { Requested battery voltage }\end{array}$

The authors are with the School of Electrical Engineering, KTH, Royal Institute of Technology, Osquldas vagen 10, 10044 Stockholm, e-mail: (risseh@kth.se; hansi@kth.se). and Universitè Paris Diderot e-mail: (christophe.goupil@univ-paris-diderot.fr)

$\begin{array}{ll}\mathrm{Si} & \text { Silicon } \\ \mathrm{SiC} & \text { Silicon carbide } \\ \text { TEG } & \text { Thermoelectric generator } \\ \text { TEM } & \text { Thermoelectric module }\end{array}$

\section{INTRODUCTION}

A CCORDING to the European commission the transport sector is responsible for $25 \%$ of the emissions of the greenhouse gases today. In fact, the low efficiency of the internal combustion engine (ICE) in vehicles is responsible for the considerable amount of greenhouse gas emissions from the transport sector. For the same reason, a significant amount of fuel energy converts to heat during the combustion process, and goes directly through the exhaust system and out to the ambient. According to J. Haidar et al. up to $35 \%$ of fuel energy converts to waste heat and escapes from the exhaust system in a diesel engine [1]. The efficiency of ICEs in that case may be $34 \%$ i.e. $140 \mathrm{~kW}$ waste heat for a larger $400 \mathrm{~kW}$ diesel engine. However, the average efficiency of an ICE over driving time may be as low as $15 \%$ [2]. Taking advantage of thermoelectricity the waste heat in the exhaust gases can partly be recovered and converted to useful electrical energy, which can be fed back into the electrical system of the vehicle. This action will relieve the alternator and the ICE, improving the overall efficiency and the fuel consumption. Thermoelectric generation is based on the Seebeck effect and can be implemented as a single thermoelectric module (TEM), usually with large number of thermo-couples. TEM is a compact solid-state device producing no pollutants and no need for maintenance, which converts heat flow to electrical power. Thermoelectric generators (TEG) have been used in different applications and power ranges, as heat harvesting systems or in cases where supplying electrical power in commercial ways are impossible [3]. For instance, TEGs have been used in medical applications to supply pacemakers [4], [5], aerospace [6]-[9] and in military applications [10], [11]. Thermoelectricity has also been combined with photovoltaic systems to harvest heat energy [12], [13].

Several studies on waste heat recovery (WHR) in automotive applications have been performed in recent years [14]-[16]. Srinivasan et al. found that TEGs in light- and heavy duty vehicles have the capability to generate $2-3.5 \mathrm{~kW}$ electrical power [17]. In another investigation Q.E. Hussain et al. discovered that in a hybrid vehicle where the ICE 
does not run continuously, the mass of the TEG affecting the time-constant is an important parameter to consider. They proposed a TEG for a $2.5 \mathrm{~L}$ gas-electric hybrid vehicle recovering 300-400 W under an EPA highway driving cycle [18]. According to Arsie et al. $449 \mathrm{~W}$ could be obtained using a TEG in a personal car equipped with a $70 \mathrm{~kW}$ diesel engine [19]. D. M. Rowe et al. measured $315 \mathrm{~W}$ electric power from a TEG in a family-size $1.5 \mathrm{~L}$ car [20] and also J. C. Bass et al. reported about a 1-kW prototype-TEG, which was designed for a Cummins NTC 350 diesel engine [21].

In order to completely utilize the advantages of a TEG, the design of the electrical power conditioning system is extremely important. N. A. Zarkadis et al. performed a study on the electrical system of a TEG for marine applications, where a high-ratio step-up converter was proposed and simulated [22]. In [23] and [24] extensive studies have been conducted on the control system of a converter connected to an emulated TEG. Moreover, Zhang et al. conducted a study where a prototype of a thermoelectric-photovoltaic hybrid system and its power conditioning system were designed. This experiment, using an induction heater to heat up the hot side of a real TEG, was performed in a laboratory [25].

Thermoelectric effects are complex phenomena where different physical actions are affecting each other simultaneously. Therefore, a TEG-system needs to be investigated under real operating conditions considering the thermal, mechanical, and electrical systems [26]. Although many studies have been performed in this field, there is a lack of investigations on electrical power management systems with a large number of TEMs, operating under real conditions where all physical effects are considered. In a well-designed TEG the connection of TEMs, the converter topology and the control system are important parts of the electrical power management system. However, the impact they have on the entire system from efficiency-, weight- and cost point-of-view has never been studied for a large-scale TEG operating under real conditions. The impact of the electrical arrangement of a TEG is especially important in automotive applications, in which there are restrictions regarding the volume and weight and where the heat source and cooling capacity are limited. It has to be mentioned that studying thermoelectricity using temperature-controlled heater and/or cooler, emulates an unlimited heat- source or sink, resulting in over-dimensioned power management system. Therefore, research on suitable power conditioning systems for TEGs operating on vehicles under real conditions is on demand.

Recently the authors of this paper representing $\mathrm{KTH}$ (Royal Institute of Technology) together with Scania, TitanX, Eberspaecher and Swerea IVF designed, manufactured and tested two TEGs on a drivable HDV. The TEGs consist of 464 TEMs and were operated under real conditions, with exhaust gases on the hot side and coolant from the vehicle cooling system on the cold side. The TEGs were communicating with the on-board computers reporting the status and operating conditions. The entire system needed to fulfill all requirements and safety regulations that on-board components have to meet in a drivable vehicle. The aim of the main study was to high-light the advantages and limitations of TEGs in real-scale commercial vehicles [16]. Moreover, the objective of the main study was to ascertain the amount of the actual net power (=gross power-all hydraulic and electrical losses) that can be obtained from a full-scale TEG in a HDV. Generally, a TEG system consists of heat exchangers (HXs), a cooling system, a number of TEMs and an electrical power management system. In this paper, the last mentioned subsystem i.e. the design of the electrical power management system, which have to handle the gross power of the TEGs, are discussed. The TEGs were developed to operate on a HDV (DC13-10-440 Euro6-12.74 L-2300 Nm-440 kW), considering power variations and the thermoelectric effects. Furthermore, the obtained efficiencies of the power converters, using two different types of semiconductor devices, are compared and also an optimum connection strategy for the TEMs is proposed. To the best knowledge of the authors this is the first time an extensive study on the entire electrical power management system, designed for a TEG on-board a real-scale and drivable HDV, is presented.

In next Section a short overview of the complete system and requirements for the power conditioning system will be presented. The thermoelectric effects and their relations with the electrical effects will be discussed briefly in Section III. In Section IV the important parameters for designing a suitable power management system, as well as efficiency maps for the converters, based on experiments, are presented. In Section V the experimental results on the gross electrical power of the TEGs, collected from an HDV running under real conditions, will be presented and lastly the conclusions are given in Section VI.

\section{Electrical System OVERVieW}

During the pre-study Scania localized the possible heat sources to be used for the TEG in the HDV. Due to the amount of available heat power, temperatures and the added hydraulic and pump losses, the most suitable heat sources were determined to be the After treatment system (ATS) and the Exhaust gas recycling system (EGR) [16]. Therefore, two main TEGs were designed to recover the heat power from the ATS and EGR. When the heat flux passes through a TEG, an electromotive force is produced which can supply an electrical load. Since the voltage and the current are functions of the temperature difference $(\Delta T)$ across each module in a TEG, the variation in temperature will change the internal resistance, output voltage and thereby the output power of the TEG. Therefore, connecting a number of TEMs in a string with different $\Delta T$ will cause additional power loss. In fact, it is beneficial to divide a large TEG into smaller units where the local $\Delta T$ s are close to each other. Therefore in this study, each TEG was divided into four sub-TEGs and in order to control the power flow from the TEGs to the electrical system of the vehicle, $2 \times 4$ identical high efficiency inter-leaved DC/DC converters were designed, see Fig. 1. A more detailed explanation about the local temperature differences in a TEG is given in Section IV-A. 


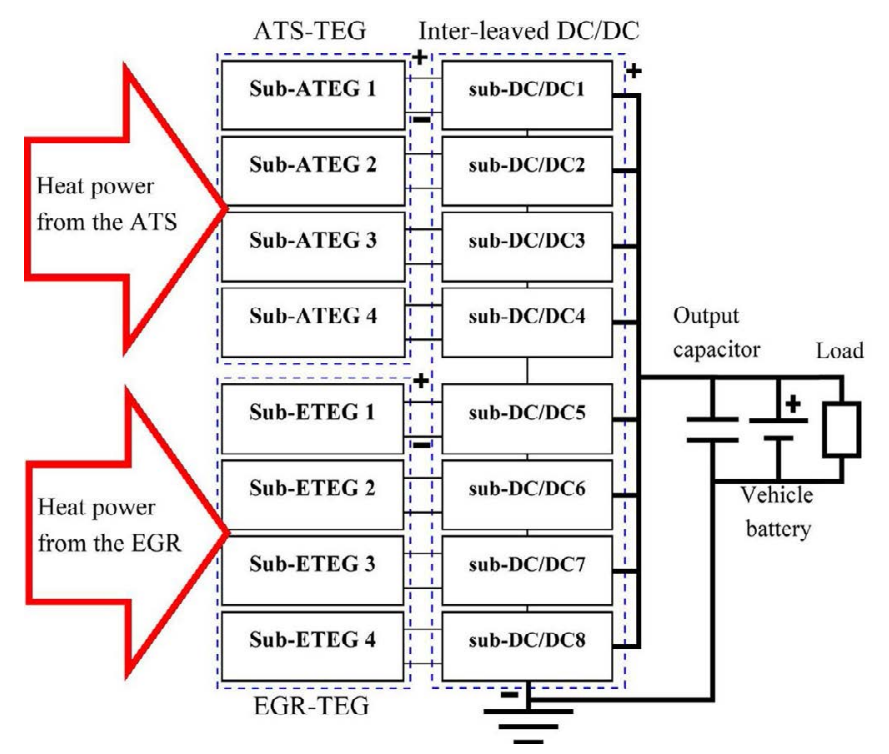

Figure 1. An overview of the TEG-system on the HDV. Due to the local temperature differences each TEG was electrically divided into 4 sub-TEGs and connected to individual inter-leaved sub-DC/DC converters.

According to Scania, the operation of an ICE in an HDV can be described by the 9-steady-state-points (9-LHC) which together create the long haulage cycle. In other words, 9-LHC emulates the real driving conditions for a long haulage HDV. The most important parameters in the 9-LHC, provided by Scania, are presented in Table I.

The open circuit voltage $\left(V_{O C}\right)$ and internal resistance $\left(R_{i n}\right)$ of each sub-TEG are the two most important parameters for designing the sub-converters. These are functions of the load of the ICE described by 9-LHC and analytically calculated. Since there are 8 sub-TEGs operating at 9 different LHCs, only values for one sub-TEG, is presented in Table II later on.

Table I

TABLE SHOWS THE EXHAUST GAS TEMPERATURES IN THE ATS AND THE EGR AS A FUNCTION OF THE SPEED AND LOAD OF THE ENGINE. THE MEASUREMENTS PRESENTED IN THIS TABLE ARE PROVIDED BY SCANIA.

\begin{tabular}{|l|l|l|l|l|l|l|l|l|l|}
\hline LHC & 1 & 2 & 3 & 4 & 5 & 6 & 7 & 8 & 9 \\
\hline $\begin{array}{l}\text { Engine } \\
\text { Speed[RPM] }]\end{array}$ & 1000 & 1000 & 1000 & 1150 & 1150 & 1300 & 1300 & 1300 & 1300 \\
\hline $\begin{array}{l}\text { Relative } \\
\text { Load[\%] }\end{array}$ & 25 & 50 & 100 & 25 & 75 & 25 & 50 & 75 & 100 \\
\hline $\begin{array}{l}\text { ATS } \\
\text { Temp. }\left[{ }^{\circ} \mathrm{C}\right]\end{array}$ & 248 & 347 & 386 & 259 & 352 & 251 & 323 & 346 & 396 \\
\hline $\begin{array}{l}\text { EGR } \\
\text { Temp. }\left[{ }^{\circ} \mathrm{C}\right]\end{array}$ & 318 & 452 & 551 & 335 & 489 & 325 & 425 & 481 & 560 \\
\hline
\end{tabular}

\section{THERMOELECTRICITY}

When the junctions of two dissimilar conductors $(A$ and $B$ in Fig. (2)) are exposed to a temperature gradient, the thermal energy will be transported from the hot junction to the cold junction. The transportation of the heat causes movement of charge carriers in the conductors, and creates an open circuit voltage called relative Seebeck electromotive force. This phenomenon is known as Seebeck effect. The temperature difference generates the voltage, and the heat flow through the thermoelectric elements drives the electrical current to an external load [27], [28].

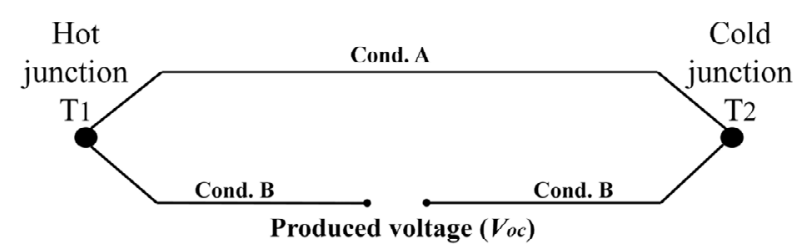

Figure 2. Due to the Seebeck effect the applied temperature gradient at the junctions causes an open circuit voltage.

The resulting voltage $V_{o c}$ is a function of temperature difference and material properties and can be described by

$$
V_{o c}=\int_{T_{1}}^{T_{2}}\left(\alpha_{A}-\alpha_{B}\right) d T=\left(\alpha_{A}-\alpha_{B}\right)\left(T_{1}-T_{2}\right),
$$

which can be rewritten as

$$
V_{o c}=\alpha \Delta T,
$$

where $T_{1}$ and $T_{2}$ are the temperature at the cold and hot junctions, $\alpha_{A}$ and $\alpha_{B}$ are the absolute Seebeck coefficient of each conductor, respectively and $\alpha$ is the differential Seebeck coefficient.

Typically, 127 to 254 pieces of highly doped n- and p-type semiconductor elements, referred to as a thermocouple, are sandwiched between two ceramic plates and form a thermoelectric module (TEM), see Fig. 3. In order to provide higher power a number of TEMs may be be connected together, which create a thermoelectric generator (TEG).

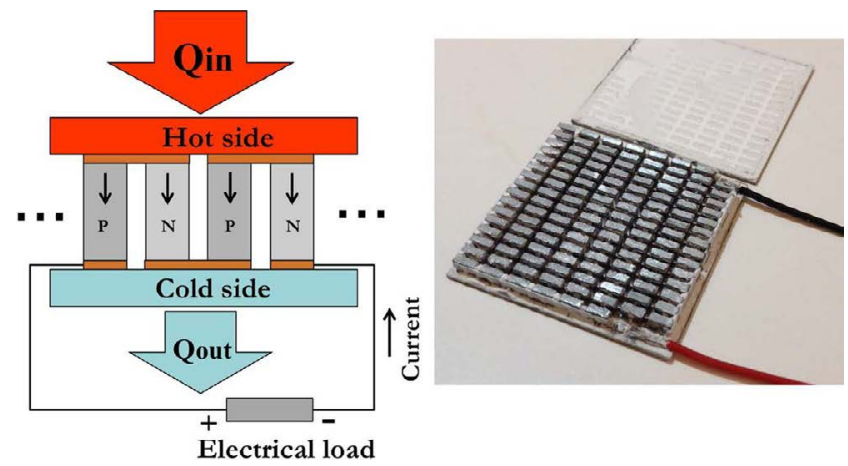

Figure 3. The figure shows the leg-configuration, the direction of the heatand electrical current in a TEM (left), and a typical commercial TEM made by a large number of $\mathrm{n}$ - and p-type semiconductor thermocouple (right).

During steady-state operation, a TEM can be modeled as an ideal voltage source $V_{o c}$ with an internal resistance $R_{i n}$ in series. From the energy balance, the produced output power of a TEM, $P_{e l}$ can be derived by:

$$
P_{e l}=Q_{\text {in }}-Q_{\text {out }}=\alpha I \Delta T-R_{\text {in }} I^{2},
$$

where $Q_{\text {in }}$ and $Q_{\text {out }}$ are the thermal power entering to the hot side and releasing from the cold side respectively, $I$ is the electrical current, and $R_{i n}$ is the internal resistance of the TEM. It has to be mentioned that studying the parameters in (3) alone, will not give complete information about the performance of the thermoelectric device. The other parameters that need to be considered in order to determine the 
performance of a TEM are dependent on the device material. An ideal thermoelectric device would have an infinite large electrical conductivity and Seebeck coefficient, and would be able to keep a large temperature difference, which is achieved by a low thermal conductance. The dimensionless figure-of-merit, $Z T$ is defined in (4) and gives the rate of performance of a thermoelectric device.

$$
Z T=\frac{\alpha^{2} \sigma}{\kappa} T
$$

where $\sigma$ and $\kappa$ are the electrical- and the thermal conductivity respectively, and $T$ is the absolute temperature [26], [29]. Since the thermal and electrical conductivities are correlated and dependent on the charge carrier concentration, a large $Z T$ is obtained by optimizing these parameters through the carrier concentration [30].

\section{Electrical Power Management of the TEG}

A TEG is made of a number of TEMs, and in a vehicle there are some restrictions that influence that number and the design of the TEG. The most important factors are the available heat power and the space dedicated for the TEG in the vehicle. The heat power is varying with the engine load and the gas mass flow, which are dependent on the type and size of the engine. In this study two different TEGs were designed and placed in the exhaust system of a Scania HDV, one downstream ATS and the other upstream EGR [16]. The design of the TEGs was based on 9-LHC where the speed of the ICE and the load is varying in a wide range, which results in variations in the exhaust temperatures and the gas mass flow. According to the 9-LHC, the gas temperatures in the ATS change between 248 and $396{ }^{\circ} \mathrm{C}$, and between 318 and $560{ }^{\circ} \mathrm{C}$ in the EGR depending on the load of the ICE.

The temperature variations in the exhaust gases will cause two issues in the electrical part of the system. Since, the output voltage $V$ of the TEG is a function of the temperature difference $(\Delta T)$ over the TEMs, the output voltage will follow the temperature variations. At the same time as the temperatures and the voltage of the TEMs change, the internal resistance $\left(R_{i n}\right)$ of the TEMs will change as well. Due to the reduction of mobility of the carriers in the semiconductor with increased mean operating temperature $\left(T_{m}\right)$, the resistivity of the semiconductor in a TEM increases. Therefore, a TEM produces less power for same $\Delta T$ at a higher $T_{m}$. In Fig. 4 the behavior of a HZ-20 module from HiZ as a function of $T_{m}$ is shown. Here, the $\Delta T$ is kept constant at $50{ }^{\circ} \mathrm{C}$ but it can be seen that $R_{i n}$ is increasing with increased $T_{m}$. It should also be noted that the Seebeck coefficient of thermoelectric elements is also temperature dependent therefore the open circuit voltage of the TEM is also varying although $\Delta T$ is fixed. The variation of the internal resistance and the voltage of the TEMs give rise to the characteristics shown in Fig. 5, where two different $\Delta T$ results in two voltage-, current- and power functions.
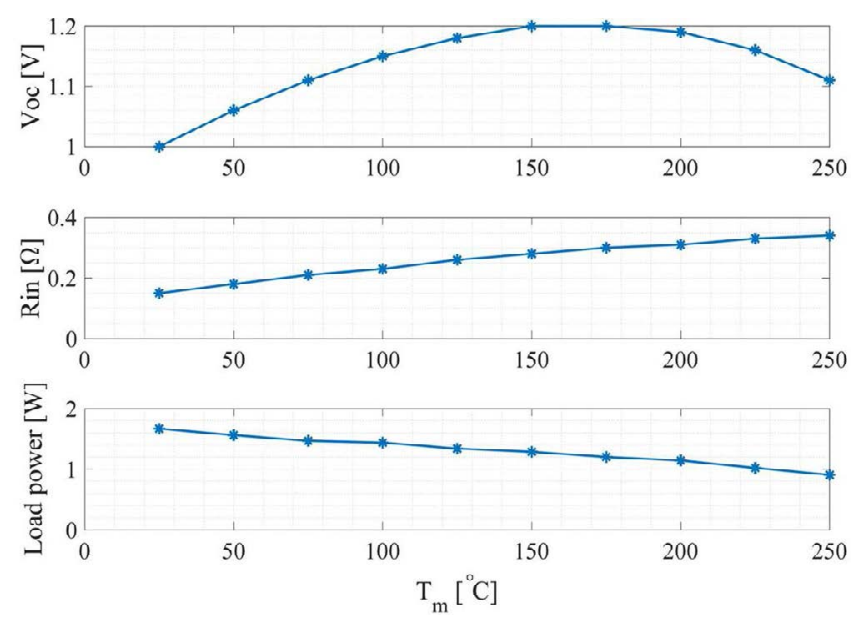

Figure 4. The internal resistance, open circuit voltage and power of a HZ-20 module as a function of the mean operating temperature $T_{m}$. Temperature difference, $\Delta T$, is kept to $50^{\circ} \mathrm{C}$.

Since the voltage of the electrical system of the vehicle controlled by the alternator while the voltage and power of the TEG vary, clearly a power conditioner between the TEG and the electrical system is needed. The aim of the power converter is to control the voltage and search for the maximum available power at different $\Delta T$ s. Generally TEMs have a low conversion efficiency, and for that reason the power conditioner and the other part of the system have to operate with highest possible efficiency over a large range of power.

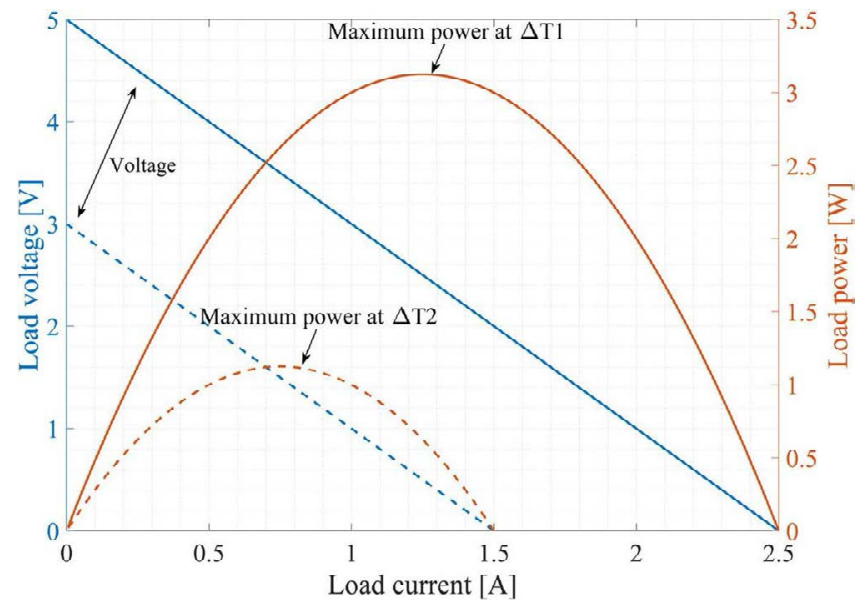

Figure 5. Variations of the temperature in the exhaust system give rise to variations in the internal resistance and different V-I-P curves, as a function of $\Delta T$. This is an example showing the behavior of the output power and voltage of a TEM at two different $\Delta T$ s as functions of current.

\section{A. Connection of Thermoelectric Modules}

The design of the HX, based on the available space and the heat power, dictates the number of TEMs. Moreover, the type of the HX will determine the temperatures at the hot- and cold sides, allowing to predict the electrical power each TEM will generate. However, the analytically calculated power for each TEM can not be added together to predict the total power of the TEG. In fact, the TEG power will be affected by the electrical connections between the TEMs. 
The maximum delivered power from a TEM (or a TEG) to a load is obtained when $R_{i n}=R_{\text {Load }}$, i.e. the internal resistance of the module is matched with the load. It is important to mention that $R_{\text {in }}$ of a module (or a TEG), which has to be considered for the maximum power tracking, is the effective value of the internal resistance. The effective internal resistance is a function of thermal conductance of the module(s) itself, as well as the thermal conductance between the heat- source and sink $\left(\kappa_{\text {hot }}\right.$ and $\left.\kappa_{\text {cold }}\right)$ [31], see fig. 6 .

The maximum output power $P_{R L \max }$ of a single module can be determined by,

$$
P_{R L \max }=\frac{V^{2}}{4 R_{i n}}
$$

while the maximum output power of $n$ number of TEMs creating a TEG, connected in series or in parallel is obtained by

$$
P_{R L \max -\text { series }}=\frac{1}{4} \frac{\left(\Sigma V_{n}\right)^{2}}{\Sigma R_{n}}
$$

and

$$
P_{R L \text { max-parallel }}=\frac{1}{4} \frac{\left(\sum \frac{V_{n}}{R_{n}}\right)^{2}}{\sum \frac{1}{R_{n}}},
$$

where $V_{n}$ is the open circuit voltage and $R_{n}$ is the internal resistance of each specific TEM. Clearly, when the TEMs operate in similar conditions, the voltages and the internal resistances of all modules are the same. Therefore, the power obtained by (6) and (7) will have the same value, i.e. the electrical connection of the TEMs does not affect the total output power [32]. However, in practical applications there are constraints that give rise to different operating conditions for each TEM. Y. Apertet et al. and A. Vargas-Almeida et al. investigated the impact of TEMs' thermal and electrical connections on the performance of a TEG [33], [34]. In order to analyze a TEM thoroughly the model in Fig. 6 was used. Employing the Onsager compact expression [35] where Joule losses are disregarded, the system can be described by

$$
\left(\begin{array}{c}
I \\
I_{Q}
\end{array}\right)=\frac{1}{R_{i n}}\left(\begin{array}{cc}
-1 & \alpha \\
\alpha \bar{T} & \alpha^{2} \bar{T}+R_{i n} \kappa_{I=0}
\end{array}\right)\left(\begin{array}{c}
\Delta V \\
\Delta T
\end{array}\right),
$$

where $I$ and $I_{Q}$ are the electrical- and thermal current respectively, and $\Delta V$ is the voltage over the electrical load. $\Delta T$ is the temperature difference $\left(T_{h M}-T_{c M}\right)$ across the module, $\bar{T}$ is the average temperature and $\kappa_{I=0}$ denotes the thermal conductance at zero electrical current. From (8) the electrical current and thermal current are obtained as

$$
\begin{gathered}
I=\frac{\alpha \Delta T}{R_{i n}+R_{L}}, \\
I_{Q}=\alpha \bar{T} I+\kappa_{I=0} \Delta T .
\end{gathered}
$$

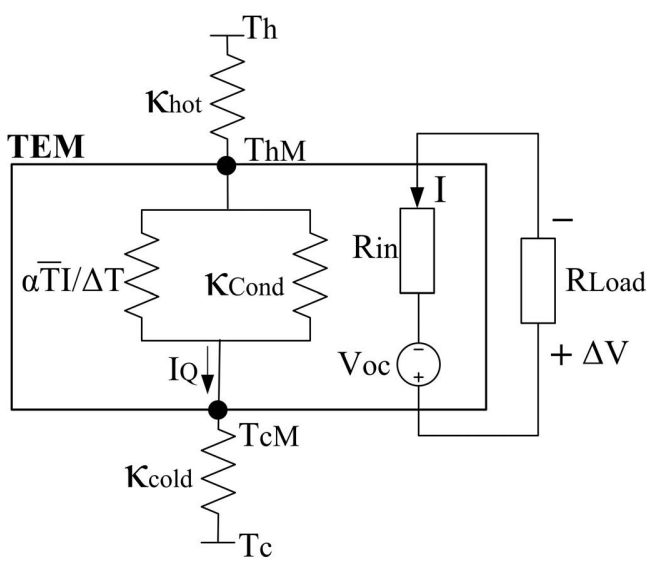

Figure 6. The electrical and thermal model of a TEM.

Combining (9) and (10) yields the relation between the thermal current $I_{Q}$, zero current thermal conductance $\kappa_{C o n d}$ and the thermal conductance associated with the electrical current $\kappa_{\text {Conv }}$, i.e.

$$
I_{Q}=\left(\frac{\alpha^{2} \bar{T}}{R_{\text {in }}+R_{L}}+\kappa_{I=0}\right) \Delta T,
$$

which can be expressed as

$$
I_{Q}=\left(\kappa_{C o n v}+\kappa_{C o n d}\right) \Delta T=\kappa_{T E G} \Delta T
$$

where

$$
\kappa_{\text {Conv }}=\frac{\alpha^{2} \bar{T}}{R_{\text {in }}+R_{L}} .
$$

Equations (11) and (12) show that not only the electrical current but also part of the thermal current can be controlled by the total resistance in the circuit. This is an excellent tool when the heat source and the cooling system have a limited capacity, as in the case of vehicle applications. This gives a capability of controlling the thermal current by adjusting the electrical current, and vice versa whenever it is necessary, for instance to protect the TEMs or cooling circuit from over heating. Furthermore, since a large electrical current increases the thermal current through a module, a low-current TEG is preferred in a system with limited cooling capacity, in order to keep the $\Delta T$ on an acceptable level. This can be achieved by connecting a number of TEMs in series to increase the internal resistance of the TEG. In [36] Gao Min showed that the relation between thermal and electrical current can also be used to increase the conversion efficiency by $40 \%$, and thereby the output power by operating a TEM in an electrical pulse-mode system.

Another issue regarding the connection of the TEMs is the mismatch caused by the applied mechanical force on different TEMs in the system. In real applications, where a large number of TEMs are used, it is impossible to ensure identical applied force of all TEMs. A force mismatch that causes a lower $\kappa_{\text {hot }}$ and $\kappa_{\text {cold }}$ on one module than the others, will lower the internal resistance and voltage of that particular module. If all modules are connected in parallel and the requested current from the load is low, or in the case of failure when the 
output of the TEG is completely disconnected from the load, the module with lower internal resistance will not generate any power but may consume power from the other modules. This issue was investigated in [37] where three TEMs were characterized and exposed to different temperatures. It was suggested that further investigations on systems with larger number of TEMs must be performed. Therefore, in this study, experiments were performed in order to propose the most suitable TEM-connection for the designed HXs.

Two connection cases were studied; all modules in series and all modules in parallel. 14 TEMs from HiZ were chosen and connected together. In both cases all TEMs except one were exposed to $T_{h}=200{ }^{\circ} \mathrm{C}$ and $T_{c}=50{ }^{\circ} \mathrm{C}$ and the last module (the unmatched TEM) was exposed to $T_{h}=170{ }^{\circ} \mathrm{C}$ and $T_{c}=50{ }^{\circ} \mathrm{C}$. Figure 7 shows the power and current as functions of load resistance for the series and parallel connection. The upper part of Fig. 7 shows the current through all the modules in the series connection (red line nr.1), the current of one of the matched modules (green line nr.2), and the current through the unmatched module in the parallel configuration (blue line nr.3). The middle and lowest graphs show the output powers of the whole strings of the TEMs for parallel and series connection respectively. The currents and the powers are plotted as functions of the load resistance. Note that the lowest graph is plotted for very small load resistance values. The maximum power is obtained at $R_{L}=4 \Omega$ for the series configuration, because at that point the total internal resistance of the TEMs is equal to the load resistance $\left(R_{L}=R_{\text {in }}=4 \Omega\right)$. Likewise, in the parallel configuration the maximum extracted power is generated at $R_{L}=R_{i n}=$ $18 \mathrm{~m} \Omega$. As will be explained in subsection IV-B4, the maximum power point tracker (MPPT) continuously adjust the load current such that the output power varies between maximum available power and for instance $90 \%$ of the maximum power. This results in an average extracted power of approximately $95 \%$ of the maximum power. In that case, the series connection results in a significantly wider operating range $\left(2 \Omega<R_{L}<6 \Omega\right.$ at $\left.R_{\text {in }}=4 \Omega\right)$, compared to the parallel connection $\left(12 m \Omega<R_{L}<29 m \Omega\right.$ at $R_{\text {in }}=18 \mathrm{~m} \Omega$ ).

This behavior is due to the larger internal resistance of the series connection and is extremely important when employing an MPPT. The small operating region of the parallel connection results in difficulties to search for the highest available power. In this case, small changes in the load current made by the converter, will result in significant changes in the output power and thereby cause oscillations. Moreover, as shown in the upper graph in Fig. 7, the current of the unmatched TEM changes direction from negative to positive when the load resistance increases above $70 \mathrm{~m} \Omega$. A positive current indicates that the module consumes electrical power. For instance, at $R_{L}=100 \mathrm{~m} \Omega$ the current into that module is $0.64 \mathrm{~A}$, indicating that the power generated by the other TEMs is consumed by the unmatched TEM. The current into the unmatched module will increase to $3 \mathrm{~A}$ at $R_{L}=50 \Omega$. A module which consumes power acts as a Peltier element and will actively pump the heat from the hot side to the cold side, and thereby decrease the temperature differences of the nearby modules as well. In case of failure, if the TEG becomes disconnected from the load, or if the requested power to the load (converter) is small, the unmatched TEM will consume $12 \mathrm{~W}$ from the other modules. This is equal to $7.5 \%$ of the total power generated by the whole string. This behavior is a highly undesirable and arises in a parallel configuration when the contact forces on all TEMs are not identical. This has to be considered when a larger number of TEMs are used and/or the differences in $\Delta T$ over the TEMs are large. Furthermore, the current in the series connection through all modules at maximum power is $6.7 \mathrm{~A}$, while the current through each matched module in the parallel connection is $7 \mathrm{~A}$ for this configuration. According to (10) the system with higher electrical current allows higher thermal current through the system decreasing the $\Delta T$, which is undesirable because it decreases the electrical power.

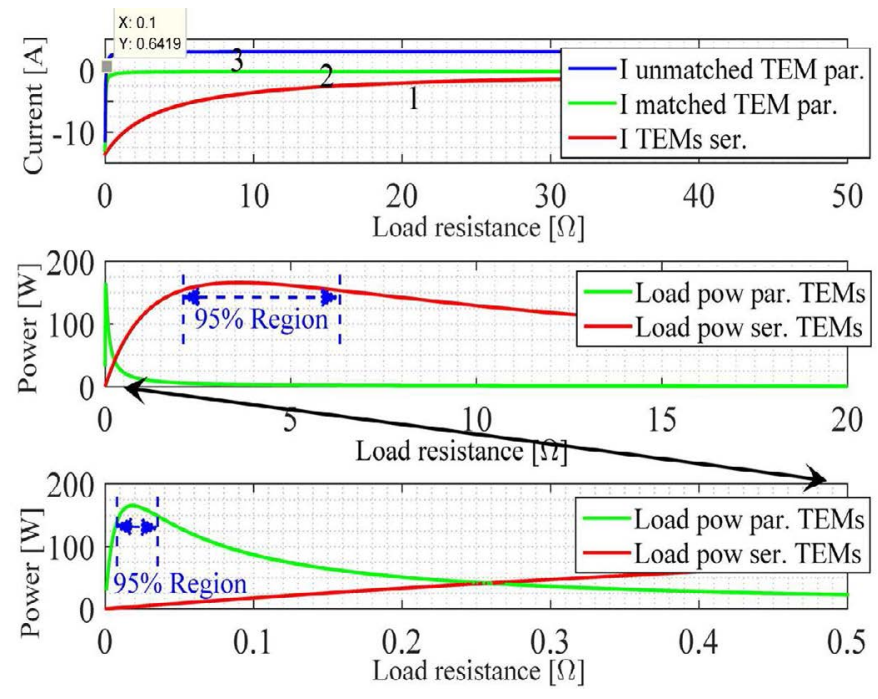

Figure 7. 14 pieces HZ-20 modules were connected to each other first in series and then in parallel. All modules expect one were exposed to $\mathrm{T}_{h}=200{ }^{\circ} \mathrm{C}$ and $\mathrm{T}_{c}=50{ }^{\circ} \mathrm{C}$. One module was exposed to $\mathrm{T}_{h}=170{ }^{\circ} \mathrm{C}$ (the unmatched TEM). The upper graph shows the total current of the series configuration (1) the current of one of the matched TEMs (2) and the current of the unmatched TEM (3) in the parallel configuration. The middle and lower graphs show the power of parallel and series connection as a function of load resistance.

Earlier it was found that modules with same $T_{h}$ and $T_{c}$ can be connected either in series or parallel and differences in output power for TEMs with same $\Delta T$ are not significant for parallel or series connection [38]. However, in practice as discussed above, it is not possible to make sure that modules that are exposed to same $T_{h}$ and $T_{c}$ will experience the same $\Delta T$. Therefore, the TEMs may be connected in series which produces a higher internal resistance and preferably increases the reliability and controllability of the system. A summary of the advantages and disadvantages of the parallel and series connection in real applications is given below.

\section{Parallel connection:}

- Needs extra space and long cables when a large number of modules need to be connected along the y-direction (see Fig. 8) . 
- Creates a large output current which requires bulky cables to be carried from the TEG to the load or a converter. The large current flows close to a cold liquid (coolant) and a hot medium (exhaust gas).

- The large current gives rise to higher electrical and thermal losses.

- Power losses are larger in case of force mismatch and this in turn will cause a mismatch in $\kappa_{\text {hot }}$ and $\kappa_{\text {cold }}$. This will lead to damage on the particular module with force mismatch.

- For TEGs in automotive applications, parallel connection requires a step-up converter with non-linear gain.

- Due to the sharper and smaller maximum power region the system will not be able to find the maximum available power and shows stability issues.

\section{Series connection:}

- Only the closest modules along the y-direction (Fig. 8) need to be connected together.

- The output current is limited by the large internal resistance and is lower than that of the parallel connection. The electrical and thermal losses are minimized due to the low current in the system.

- Lower losses and the electrical stress on mechanically unmatched modules.

- The same amount of current flows trough all TEMs.

- For TEGs in automotive applications a series connection requires a step-down converter with linear gain.

- In case of damage and open circuit of one module, the power from the complete string is lost.

There are two important issues when it comes to a large number of TEMs operating on a drivable vehicle; parallel connection will result in a large output current, and in a series connection the complete string will be lost in case of failure of one TEM. By compromising, it is possible to reduce the total output current and minimize the risk of putting out a string of TEMs while taking into account the other issues mentioned above. By looking at the design of HX in the vehicle, the most suitable connection considering the issues above, can be suggested. The design of the HX in this case can be seen in Fig. 8.

The HXs were designed to generate the same gas flow in y-direction, and based on the available heat energy and the cooling circuit the most suitable commercial TEM (Thermonamic TEP1-164-3.4) for the expected temperatures, was chosen. The TEG configuration can be seen in Fig. (8). With the same experimental procedure as in [37], a mathematical model was developed to predict the open circuit voltage and the internal resistance of the TEM for different $\Delta T$ s. The dedicated space in the vehicle allows 28 and 30 rows of TEMs in y-direction for ATS- and EGR-TEG respectively, which corresponds to 224 and 240 TEMs in each TEG. Due to the available heat power on the EGR and ATS, the output power of the ATS and EGR-TEG are slightly different. However, the electrical components and connections of both systems could be designed similarly, therefore in the following chapters the focus will be on the design of the ATS-TEG.

Assuming an ideal and identical installation of all TEMs,

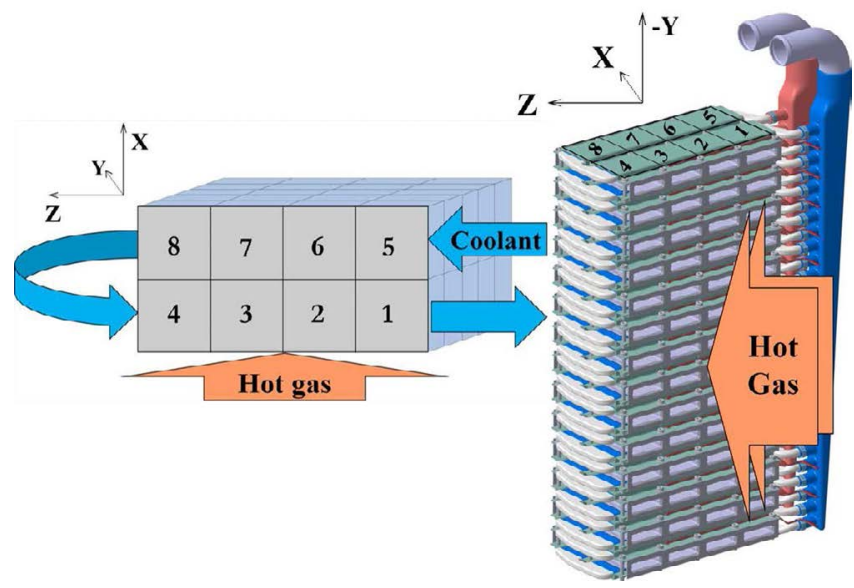

Figure 8. The figure shows the TEG and configuration of the heat exchangers. The exhaust gas flows in $\mathrm{x}$-direction and the coolant flows in z-direction as cross-counter flow configuration.

the values of $K_{\text {hot }}$ and $K_{\text {cold }}$ remain constant for the modules. In this case, the TEMs at each position in y-direction $(28$ TEMs), will experience the same $\Delta T$. As expected, the $\Delta T \mathrm{~s}$ are different for modules in position 1 to 8 in Fig. (8). The cold and hot side temperatures of each position (1-8) as a function of 9-LHC as well as $\Delta T, V_{o c}$ and $R_{i n}$ for each single TEM were determined. $\Delta T$ over each TEMs for three operating points number 1, 2 and 9 are plotted and shown in Fig. 9. As seen in this figure, because of the low heat capacity of the exhaust gasses and losses in HXs, TEMs will experience lower temperatures than the actual exhaust temperatures listed in Table I. Since the HXs are designed to give the same $\Delta T$ the in y-direction, the type of connection in each column in that direction does not affect the maximum output power. However, connecting 28 or 30 modules in parallel and in the limited space is challenging, since the TEM at the highest position has to be connected to the TEM at the lowest position. Moreover, connecting all the modules in parallel results in a low output voltage and a large output current, which needs to be carried to a step-up power converter. According to the simulations, the total output current in case of parallel connection will reach $30 \mathrm{~A}$ in each column in y-direction during LHC nr. 9, while a series connection would reduce the current to approx. $1 \mathrm{~A}$. Clearly, choosing the connection with $1 \mathrm{~A}$ is beneficial since the physical distance from the TEG to the converters may be large and depending on the available place.

The mechanical mismatch discussed earlier in this section is largest between the modules physically placed far from each other, therefore nearby modules may be connected in parallel. The group of parallel connected modules can then be connected in series with another group which reduces the total output current. It was proposed that modules may be connected in parallel in pair, and then in series with the next pair, according to Fig. 10. Due to the locally parallel connections of the two nearby TEMs, this configuration reduces the risk of power loss in the whole string if one module would fail and acts as an open circuit. In addition, the mismatch on the force contacts on the two nearby modules connected in parallel is minimum. However, in case of a significant mismatch, 


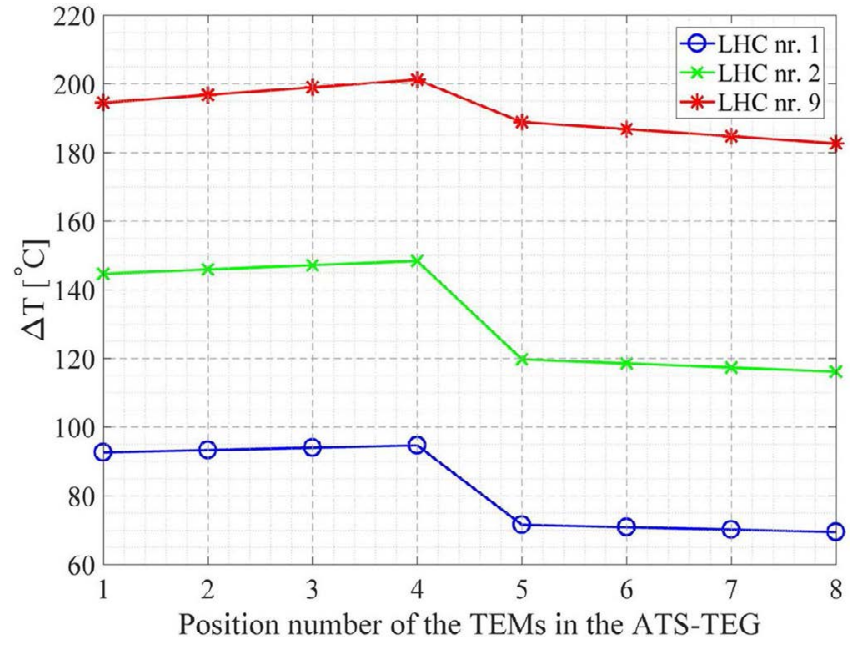

Figure 9. Temperature difference $\Delta T$ across the modules at position 1 to 8 (according to Fig. (8)) in the ATS-TEG for the lowest power produced during LHC nr. 1, mid power produced during LHC nr. 2, and the highest power produced during LHC nr. 9.

the current flowing through the module with low internal resistance is lower than for entirely parallel connected TEM string.

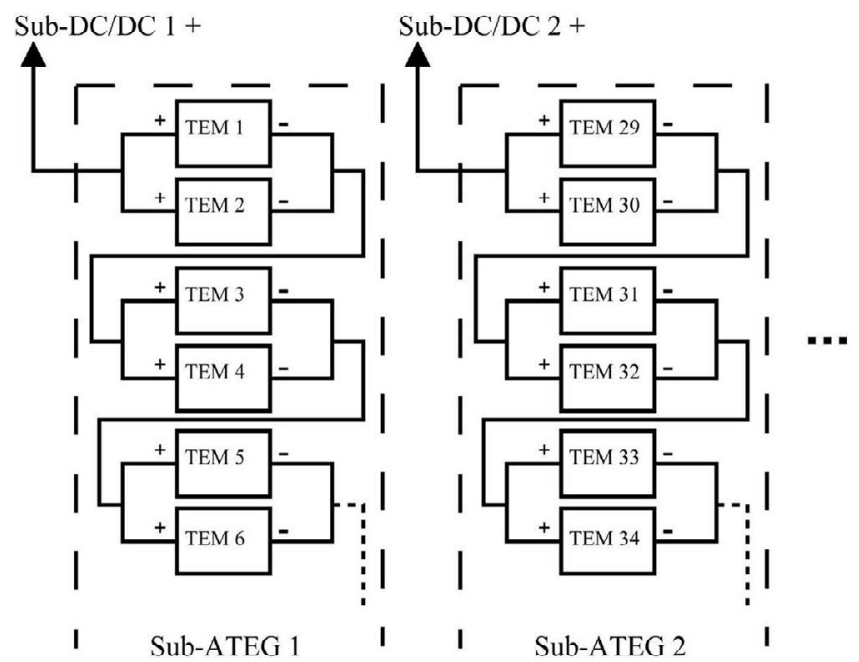

Figure 10. The final connection of TEMs in one column (along y-direction in Fig. 8) with 28 TEMs in the ATS-TEG and 30 TEMs in the EGR-TEG.

The open circuit voltage and the internal resistance for each single TEM in Fig. 8, which were obtained mathematically earlier, were used to simulate in OrCAD to hold the corresponding values of the proposed connection in Fig. 10. $V_{o c}$ and $R_{i n}$ for Sub-ATEG 1 is presented in Table II. It has to be noted that similar values as presented in this Table were obtained for each sub-TEG. Figure 11 shows the ATS-TEG when 224 TEMs are installed and prepared to be connected in strings according to the schematic in Fig. 10.
Table II

THE OPEN CIRCUIT VOLTAGES $V_{o c}$ AND INTERNAL RESISTANCES $R_{i n}$ FOR SUB-TEG 1 IN THE ATS, BASED ON 9-LHC.

\begin{tabular}{|l|l|l|l|l|l|l|l|l|l|}
\hline LHC & 1 & 2 & 3 & 4 & 5 & 6 & 7 & 8 & 9 \\
\hline$V_{o c}[V]$ & 116 & 166 & 160 & 122 & 179 & 122 & 163 & 180 & 206 \\
\hline$R_{i n}[\Omega]$ & 69 & 75 & 77 & 70 & 76 & 70 & 75 & 76 & 77 \\
\hline
\end{tabular}

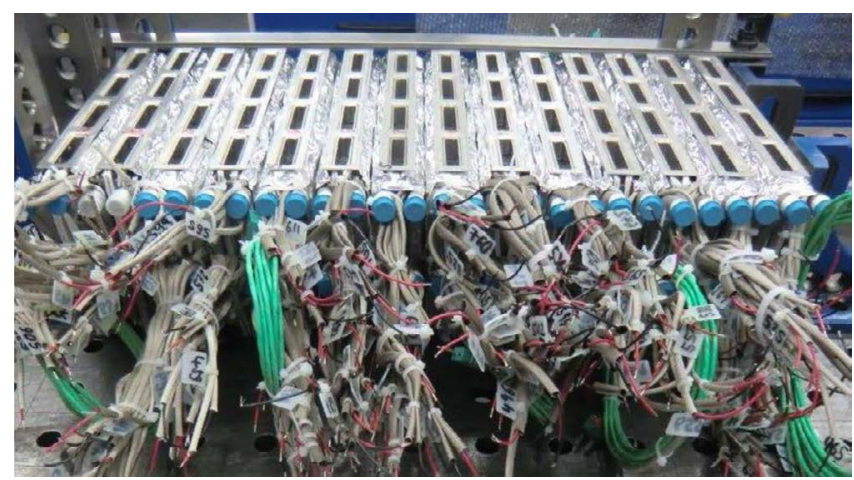

Figure 11. The figure shows the ATS-TEG with 224 TEMs prepared to be connected as four sub-TEGs.

\section{B. Power Converter}

The power converter for a thermoelectric waste-heat recovery system is essential in order to harvest as much power as possible. The reason for this is that the thermal operating point of the TEMs varies substantially. In Fig. 9 it is shown that $\Delta T$ of a TEM may vary from $70{ }^{\circ} \mathrm{C}$ to $200^{\circ} \mathrm{C}$. This means that the induced voltage and internal resistance of the TEM vary considerably, and without a controllable power converter with high efficiency very little of the energy in the heat flows can be harvested as electrical energy.

The power converter topology that may be employed to control the electrical power from a TEG is dictated by the output voltage of the TEG, which in turn is a function of the available heat power and connections of the TEMs. Generally, different types of buck-boost converters are proposed to be suitable for TEGs [22]-[24]. In [39] a SEPIC converter was proposed as the power conditioning system for a TEG to charge a $6 \mathrm{~V}$ battery. A buck-boost converter with $96 \%$ efficiency and a seamless MPPT controller was proposed in [40]. For real applications in conventional vehicles with a battery voltage of 12 or $24 \mathrm{~V}$, employing step-up converters requires low input voltage and high input current which are obtained by parallel connections of all TEMs. As discussed in Section IV-A parallel connection of TEMs has to be avoided. Buck-boost converters are, therefore, a preferred alternative. However, a power converter for TEG used in automotive applications has to contain a few components to reduce the complexity, the losses, weight and the cost of the system. The volume and weight of the power converter are important quantities to minimize on any vehicle, as they reduce available space and load capabilities and as they may have an impact on the fuel consumption. The choice of switching frequency of the power converter is important because an increase in switching frequency results in reduced volume and weight of inductors and capacitors of the converter. Unfortunately, an increase in 
switching frequency also results in increased switching losses of the power converter. This means that volume minimizations may result in efficiency reductions. The conduction losses of the converter can be influenced through the chip area of the semiconductor, and a reduction in conduction loss also implies reductions in volume and weight of the cooling system of the converter.

Requirements on output ripple from the converter are also important because this influences the expected lifetime of the battery. Again, reductions in ripples are associated with higher switching frequencies and higher switching losses. The design of the power converter, therefore, becomes a complex task which will be explained in more detail below.

1) Converter System Layout: In order to achieve a high effective switching frequency without having an excessive switching frequency per power switch, the converter system was operated using interleaved switching. As shown in Fig. 1 both the ATS-TEG and the EGR-TEG were connected such that four output channels were obtained from each of them. Each of those channels were connected to a sub-converter, consisting of a half-bridge step-down synchronous converter with an output filter inductor. Each of the filter inductor outputs were connected to the output capacitor. By phase-shifting the switching signals of the sub-converters for each TEG by a quarter period of the switching frequency, the effective switching frequency seen from the output capacitor was four times the switching frequency of each power switch.

2) Choice of switches: Each sub-converter was exposed to a certain input voltage and current, which were calculated based on the heat extracted from the exhaust gases and the connection of the TEMs. The output of the converters were connected to the electrical system of the vehicle operating at $28 \mathrm{~V}$. The maximum power that each sub-converter needs to handle were calculated to approx. $160 \mathrm{~W}\left(V_{o c}=225 \mathrm{~V}\right)$. Usually, for this kind of applications silicon ( $\mathrm{Si}$ ) MOSFETs are a good choice as switches. However, when it comes to converters for higher power with high efficiency, silicon carbide ( $\mathrm{SiC}$ ) MOSFETs may be used. The high blocking voltage, the low on-state resistance and input capacitance and $E_{O N}, E_{O F F}$, as well as capability of operation at high temperature and frequency, are the reasons making the $\mathrm{SiC}$ MOSFET as a preferred device in power electronics. However, due to the high blocking voltage of $\mathrm{SiC}$ devices, theses devices are typically compared to Si IGBTs. In other words, there is a lack of studies which emphasize possible benefits of using $\mathrm{SiC}$ MOSFETs, also in low voltage and low power applications, as a substitution for Si MOSFETs. During this part of the study, the question whether SiC MOSFETs can be used as a substitute for Si MOSFETs for lower power range, could be answered. Therefore, the efficiency of a sub-converter was compared using two different MOSFETs. First two Si-MOSFETs from Infineon (IPB200N25N3) were employed as the high- and low-side switches, see Fig. 12 for the schematic diagram of the converter. Later on, SiC-based MOSFETs from Cree (C2M0025120D) were mounted on an identical board and were tested. Some specifications of the two types of MOSFETs are listed in Table III.

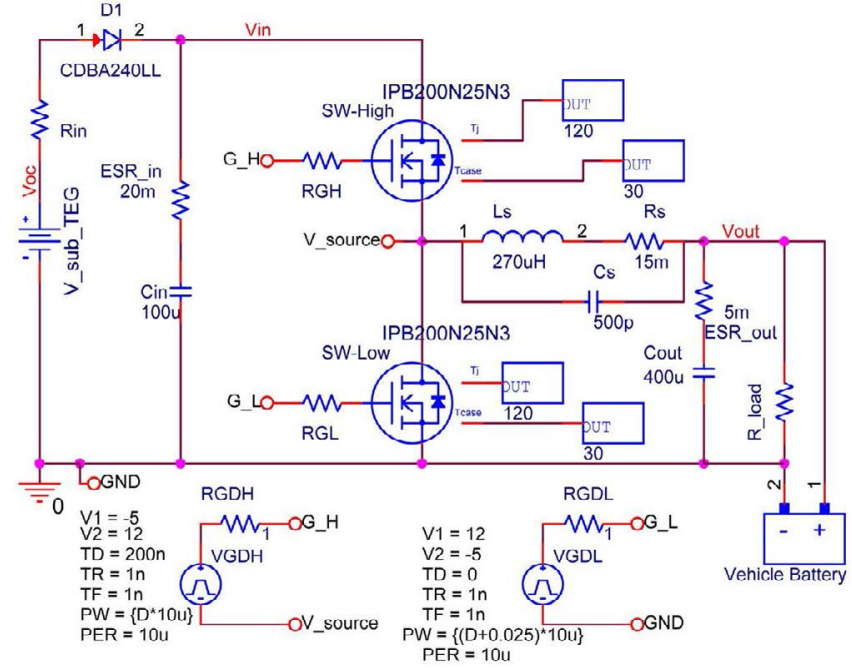

Figure 12. Schematic diagram of the a sub-converter drawn in ORCAD for simulation in PSpice.

Table III

SPECIFICATION OF TWO DIFFERENT SWITCHES USED IN SUB-CONVERTERS.

\begin{tabular}{|l|l|l|l|l|l|}
\hline Rated parameters & $\begin{array}{l}V_{D S} \\
{[\mathrm{~V}]}\end{array}$ & $\begin{array}{l}I_{D} \\
{[\mathrm{~A}]}\end{array}$ & $\begin{array}{l}R D S_{O N} \\
{[\mathrm{~m} \Omega]}\end{array}$ & $\begin{array}{l}V_{G S(t h)} \\
{[\mathrm{V}]}\end{array}$ & $\begin{array}{l}C_{i s s} \\
{[\mathrm{nF}]}\end{array}$ \\
\hline $\mathrm{Si}$ - IPP200N25 & 250 & 64 & 20 & 3 & 5.3 \\
\hline $\mathrm{SiC}$ - C2M0025120 & 1200 & 90 & 25 & 2.6 & 2.7 \\
\hline
\end{tabular}

The input voltages to the converters were calculated based on earlier simulations on each sub-TEG, and the input-, output currents were determined by

$$
\begin{gathered}
\frac{V_{\text {out }}}{V_{\text {in }}}=\frac{I_{\text {in }}}{I_{\text {out }}}=D, \\
I_{\text {out }}=I_{\text {lower }}+I_{\text {upper }},
\end{gathered}
$$

and

$$
I_{\text {upper }}=I_{\text {out }} D
$$

where $V_{\text {in }}$ and $V_{\text {out }}$ are the input and output voltages of each sub-converter respectively, $I_{\text {in }}$ and $I_{\text {out }}$ are the input and output currents, $I_{\text {lower }}$ and $I_{\text {upper }}$ are the currents through the lower and upper position switches, and $D$ is the duty ratio of the upper switch. The highest voltage the switches will experience was calculated to approximately $225 \mathrm{~V}$, and the highest current through the switches may reach $5 \mathrm{~A}$. The total losses in the switches were calculated for the highest expected power according to (17) and (18):

$$
P_{t o t_{s w}}=P_{s w}+P_{c o n d}
$$

which can be rewritten as

$$
P_{\text {tot }}=f_{s w}\left(E_{O N}+E_{O F F}\right)+R_{D S_{O N}} I_{D}^{2} .
$$

where $P_{s w}$ is the switching loss, $P_{\text {cond }}$ is the conduction loss when the switch is on, $f_{s}$ is the switching frequency, $E_{O N}$ and $E_{O F F}$ are the turn-on and turn-off switching energies. $I_{D}$ is the Drain current and $R_{D S_{O N}}$ is the Drain-Source resistance 
of the MOSFETs. The Switching losses for the SiC-MOSFET was approximately calculated to $1.2 \mathrm{~W}$ at $f_{s}=100 \mathrm{kHz}$, $V_{D S}=225 \mathrm{~V}$ and $I_{D}=5 \mathrm{~A}$. For the same conditions, the losses in the Si-MOSFET were determined to $2 \mathrm{~W}$. In other words, the losses would be reduced by $40 \%$ only by replacing the Si-MOSFETs by SiC-MOSFETs. The most important parameter affecting the losses is the lower input capacitance $\left(C_{i s s}\right)$ of the SiC-MOSFET. This not only reduces the switching losses, but also the required gate power, which is a significant contribution to the losses in this case.

In order to accurately investigate the impact of $\mathrm{Si}$ - and SiC-MOSFETs on the total efficiency of the sub-converter, the efficiency was measured using a high accuracy $(99.98 \%)$ power analyzer. The measurements were done for the 9-LHC according to Table I and for different switching frequencies. Efficiency maps for the measurements were plotted and can be seen in Fig. 13 and 14. The highest converter efficiency for both switches was obtained at $37 \mathrm{kHz}, 98.0 \%$ using $\mathrm{SiC}$ switches and $97.4 \%$ using $\mathrm{Si}$-Switches. The results may be compared with efficiencies obtained in [41] where converters for high power automotive applications were developed.

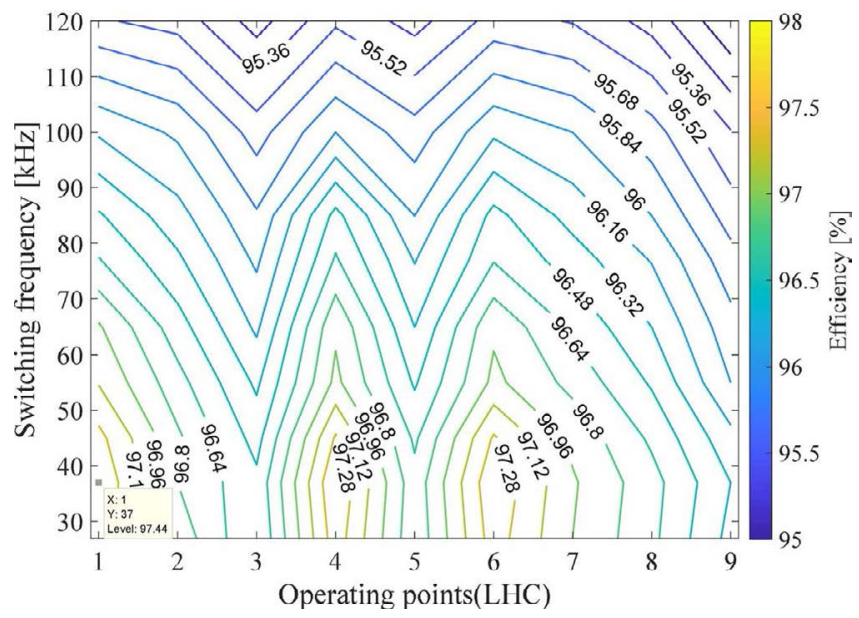

Figure 13. Sub-converter efficiency map as a function of switching frequency and LHC (power) using Si-MOSFETs as switches. Highest efficiency was $97.44 \%$ and it was obtained at LHC nr. 1 and $37 \mathrm{kHz}$.

The lower losses in SiC-MOSFETs are also reflected directly on the total efficiency of the sub-converter since both measurements resulting in Fig. 13 and 14 were performed using the same board, only the type of switches was changed from $\mathrm{Si}$ to $\mathrm{SiC}$. As seen the sub-converter using $\mathrm{SiC}$ has generally higher efficiency in all LHCs. Moreover, as seen in the figures, due to a lower input capacitance of the SiC-MOSFETs, the converter shows a smoother efficiency change as a function of switching frequency.

To eliminate the losses related to the body-diode conduction, shoot-through current and reverse current in the inductor, the switches have to be prevented from turning on or off at exactly the same time. This is adjusted by a dead-time between the upper and the lower switches. Since the switching time varies with the power, a dynamic dead-time was implemented in the control system. The start value for the lowest power (LHC1) was set to approximately $50 \mathrm{~ns}$ for the turn-on and $80 \mathrm{~ns}$ for the turn-off sequence of the upper transistor. In order to reduce

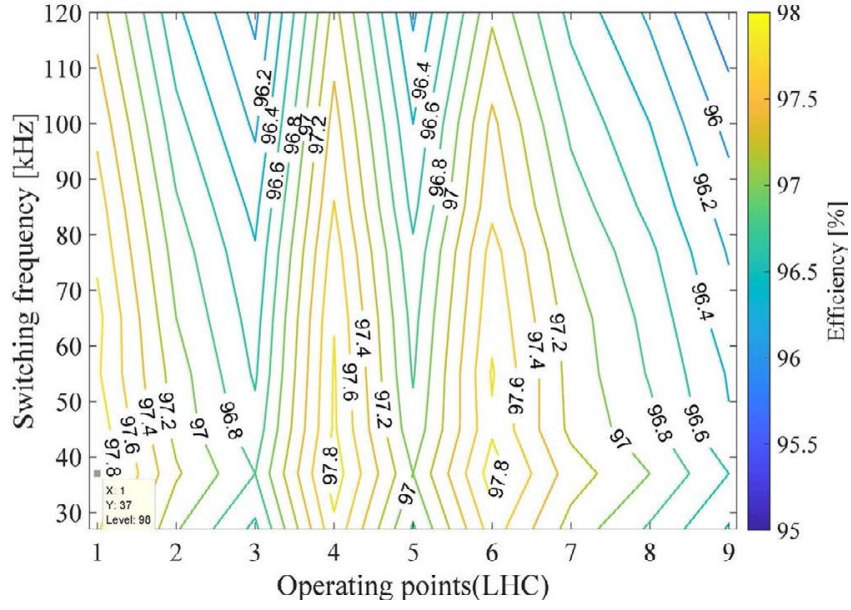

Figure 14. Sub-converter efficiency map as a function of switching frequency and LHC(power) using SiC-MOSFETs as switches. Highest efficiency was $98 \%$ and it was obtained at LHC nr. 1 and $37 \mathrm{kHz}$.

the switching losses additionally the module described in [42], [43] may be used. However, it has to be noted that no studies are conducted on reliability issues related to vibrations for that particular module.

3) Passive components: As seen in Fig. 12 there are four main passive components needed in the sub-converter, i.e. the blocking diode at the input, the input- and output capacitors $\left(C_{\text {in }}, C_{\text {out }}\right)$ and the inductor $\left(L_{S}\right)$. The purpose of the diode is to block the current from the battery flowing back to sub-TEGs. The values of the other components affect the input and output voltage ripple and the output current ripple. The voltage ripple at the input is not critical and in this design it was set to $0.1 \%$ of the input voltage resulting in a $100 \mu \mathrm{F}$ input capacitor. However, choosing the output capacitor and inductor has to be done paying attention since they are directly connected to the electrical system of the vehicle. The on-board electrical energy storage in this case was a lead-acid battery with a nominal voltage of approximately $24 \mathrm{~V}$. The recommended current ripple to such a battery is 5 A considering life time and performance of the battery. The voltage ripple is affected by the output capacitor and has not to exceed $0.5 \%$ of the nominal value. This ripple will at the same time determines the current ripple to the battery. The output voltage ripple was calculated to be $0.15 \%$ which ensures the current ripple restriction to the battery with a large marginal. Moreover, the ripple of the inductor current is eliminated by the output capacitor and thereby less important. Therefore, the current ripple was set to $30 \%$ in the calculations resulting in a $270 \mu \mathrm{H}$ inductance.

Figure 15 shows a result of such calculations for the inductor and number of turns of the winding which are functions of LHCs and the position of sub-TEGs connected to each sub-converter. The real inductor used in each sub-converter can be seen in Fig. 16.

A list of the main components with part numbers are collected and presented in Table IV. 


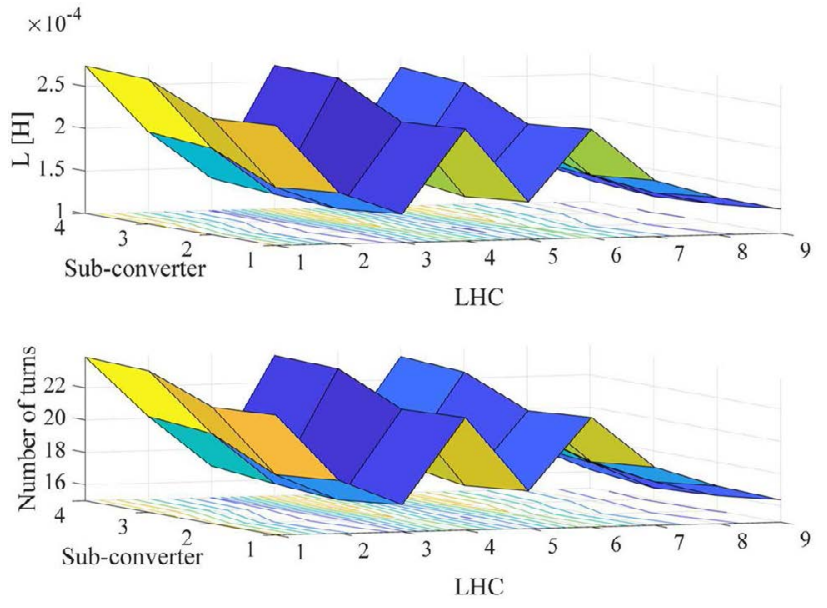

Figure 15. The plot shows the minimum inductance necessary to keep $30 \%$ current ripple in each inductors. The lower part shows the number of turns of winding resulting in the required inductance using an ETD-59 core. The maximum magnetic field in the core was set to $250 \mathrm{mT}$ in the calculation.

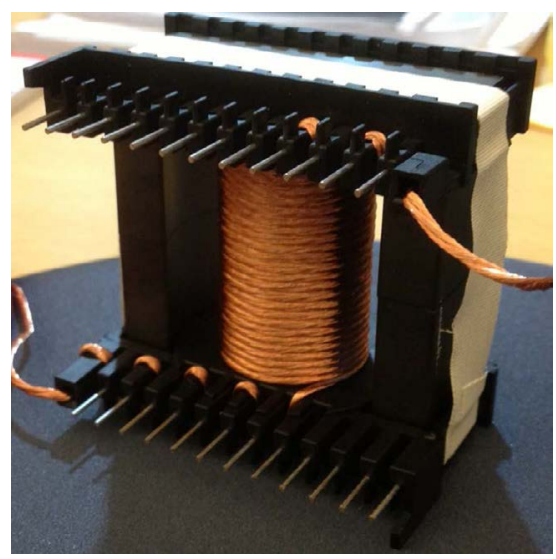

Figure 16. The inductor was made by ETD-59 core, 6 parallel Litz wire (CLI200/60) and 25 turns.

Table IV

LIST OF THE MAIN COMPONENTS USED IN POWER CONDITIONING SYSTEM.

\begin{tabular}{|l|l|l|}
\hline Component & Part number & Remarks/Function \\
\hline Switches & C2M0025120D & $\begin{array}{l}\text { SiC-MOSFETs at high- } \\
\text { \& low-side }\end{array}$ \\
\hline $\begin{array}{l}\text { Input- \& output } \\
\text { capacitor }\end{array}$ & 107 TTA350M & $1 \mathrm{~mm}$ air-gap \\
\hline Inductor core & ETD59 - N87 & $\begin{array}{l}6 \text { parallel windings, 25 } \\
\text { turns }\end{array}$ \\
\hline $\begin{array}{l}\text { Inductor } \\
\text { winding }\end{array}$ & Litz CLI200/600 & From -3 V to +15 V \\
\hline $\begin{array}{l}\text { Gate driver and } \\
\text { isolator }\end{array}$ & ADuM4224 & $\begin{array}{l}\text { PWM, ADC, CAN, } \\
\text { MPPT }\end{array}$ \\
\hline Control unit & TMDSCNCD28335 & CAN \\
\hline Transceiver & SN65HVD230 & Input and output \\
\hline Voltage sensor & ACPL-C87B-000E & Input and output \\
\hline Current sensor & LTSR 6-NP & $\begin{array}{l}12 \text { pcs. in parallel - } \\
\text { preventing the battery } \\
\text { current flowing to the } \\
\text { TEG }\end{array}$ \\
\hline Input diodes & SS16T3G &
\end{tabular}

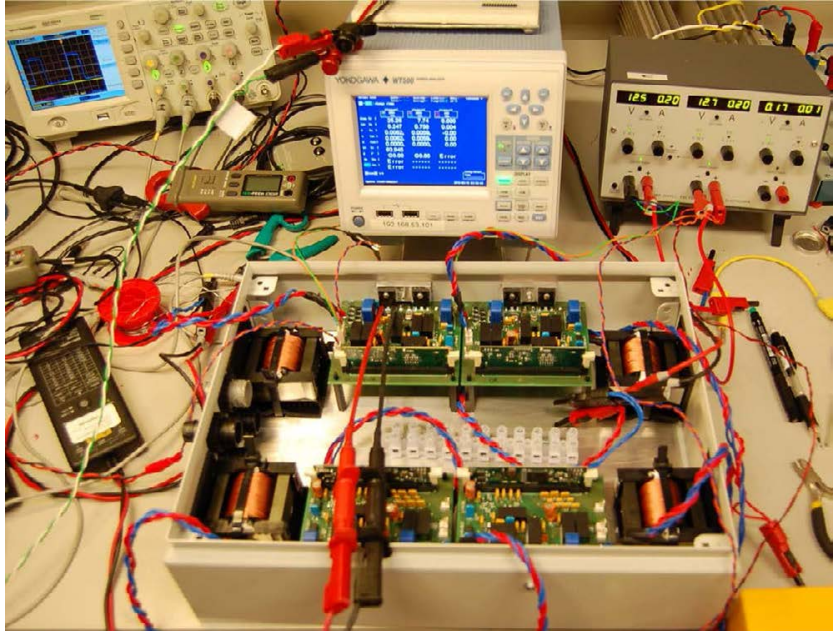

Figure 17. ATS-TEG sub-converters during tests and verifications in the lab.

4) Maximum Power Point Tracker: As mentioned in Section IV-A, in order to extract highest available power from the TEGs the internal resistance and the load resistance have to be equal. However, the variations of temperature in the exhaust system lead to variations in the voltage and the internal resistance of the TEG. This will result in, as the behavior as was shown in Fig. 5, different maximum power as a function of temperature. On the other hand, the load resistance also varies and is dependent on the condition of the electrical energy storage, the ambient temperature and the entire electrical system of the vehicle. In fact, it is impossible to measure the load resistance of the system. Therefore, the purpose of the power converter is also to adjust the load current so that $R_{i n}=R_{\text {Load }}$ is valid which leads to $\operatorname{Vin}=V o c / 2$. Moreover, since the thermodynamical system of a TEG is very complicated, and the TEG itself consists of a large number of TEMs, it is practically impossible to accurately measure the actual thermal condition for each single TEM and adjust the current for instance by using a look-up table. One way could be to measure the electrical parameters such as open circuit voltage, which can be done by disconnecting the TEG from the converter during a short period of time, i.e. few microseconds. Based on the measured $V_{o c}$, adjust the duty ratio $(D)$ of the switches until $V i n=V o c / 2$ is obtained. This needs to be done often, and as soon the vehicle driving conditions change. However, as shown in (10), the thermal current in the system is affected by the electrical current, i.e. decreasing the electrical current toward zero will in a chain reaction decrease the thermal current, $\Delta T$ followed by $V_{o c}$. In other words, measuring $V_{o c}$ would result in an unreliable maximum power tracking.

The most accurate method to extract the maximum available power from a TEG is by employing an MPPT algorithm. There are a number of different MPPTs, nevertheless the basic operation is similar; measuring the voltage and current during the operation and comparing them to the previous sampled values. In detail, the algorithm makes a small change in the control signal and notes the result of the change on the output power. If that action gives rise to a higher output power than in the previous loop, the same action will take place again in 
the next loop, otherwise an opposite action befalls. Usually, the control signal sets the duty ratio of the switches in the power converter, adjusting the current. The disadvantage of MPPT is that it will never stay at the maximum point but moves back and forth around the maximum power. Different MPPT algorithms were analyzed in [44]. Perturb and observe algorithm is one type of MPPT which showed a sufficient results in an earlier investigation at Scania, and therefore it was implemented into the control system of the power converter. The most important parameters were found to be the sampling frequency and $\Delta D$; the step-size which $\mathrm{D}$ will be changed by. A small $\Delta D$ results into a non-measurable change in the output power and thereby no action will take place. In contrast, a large $\Delta D$ leads to oscillations in the output power. The sampling frequency has the same effect, i.e. high frequency results in no change in power since the response time of the TEG is long, and low sampling frequency causes oscillations in power and consequently an inaccurate MPPT. It has to be mentioned that in a similar system as in Fig. 7 where the modules are connected in parallel, the produced $R_{i n}$ very low. In that case the converter needs to adjust the current so that $R_{L}$ is kept in the range of $12 m \Omega<R_{L}<29 \mathrm{~m} \Omega$. However, no sufficient small $\Delta D$ would be able to keep $R_{L}$ in that small region and thereby track the maximum power. Therefore, the connection between modules in a TEG producing a large $R_{\text {in }}$ is very important. In Fig. 18 the flowchart of the implemented control and MPPT algorithm is shown. The flowchart can be divided into four parts where the first one is assigned to the start-up sequence when the engine is cold and the TEGs do not generate any power. The duty ratio is set to $100 \%$, and as soon as the TEGs are able to generate power, the control system checks if the battery is able to receive any power or not (part II). If the actual battery voltage (ABV) is higher than what the main ECU requests, no power from the TEGs has to flow to the battery and therefore the duty ratio $(D)$ decreases very fast towards zero. The algorithm enters part III and IV where the actual MPPT is implemented. This occurs only if there is available power in the TEGs AND if the vehicle's main ECU decides to charge the battery. In part III, $D$ decreases by duty-step $\Delta D$. If the resulting power is higher than the previous loop the control system decreases $D$ further, if not, $D$ will be increased in part IV. The power is measured and reported continuously during the entire operation.

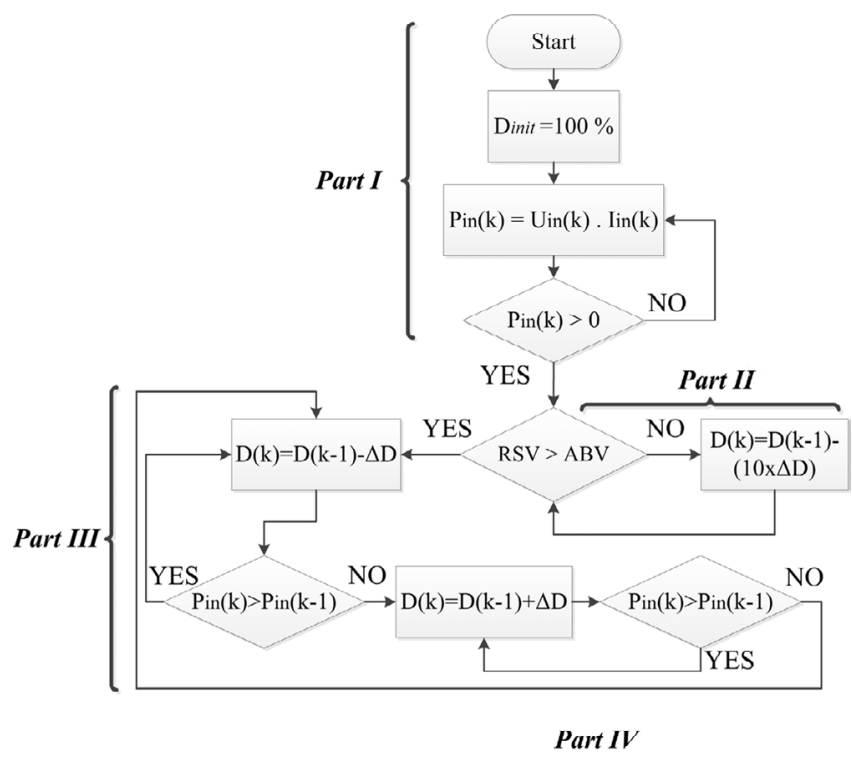

Figure 18. The flowchart shows the implemented control system of the converters including the perturb and observe algorithm as MPPT. The measured variables are the input voltage $\left(V_{i n}\right)$ and current $\left(I_{i n}\right)$ and the control parameter is the duty ratio $(D) . \Delta D$ is the step that the duty ratio will increase or decrease for each sampling $(k)$. The control system read requested system voltage (RSV) from vehicle's main ECU and compares it with the actual battery voltage $(\mathrm{ABV})$ to decide the amount of power flow from TEGs to the battery.

\section{RESUlTS}

All components operating on a real vehicle need to be completely safe and reliable before they are allowed to be connected to the vehicle. It is very important that the electrical power management system of the TEG is thoroughly tested in the laboratory before it can operate on-board since in case of failure it may affect the entire electronic system of the vehicle. After an internal evaluation from Scania the entire system was mounted on-board and tested.

The power management system of the TEGs was communicating with vehicle ECU through the CAN bus. The electrical power of the TEGs could therefore be monitored from the main ECU. The TEG system on-board the truck was first tested in a dyno-cell where the ICE could be loaded according to the 9-LHC. In a dyno-cell the speed and the temperature of the ambient air can accurately be controlled. Later on, the truck was also operated by drivers on Scania's test line, i.e in an uncontrolled environment. The sub-converters were mounted in two different boxes for each TEG, see Fig. 19. For safety reasons the temperatures inside the boxes were monitored during operation. The temperatures did not exceed $35{ }^{\circ} \mathrm{C}$ at $15{ }^{\circ} \mathrm{C}$ ambient temperature. The electrical power of each TEG from the dyno-cell measurements can be seen in Table V. In order to push the entire system to its limits, the ICE was also running at highest possible power. At this operating point, the total electrical power from the TEGs reached just above $1 \mathrm{~kW}$ [16]. 


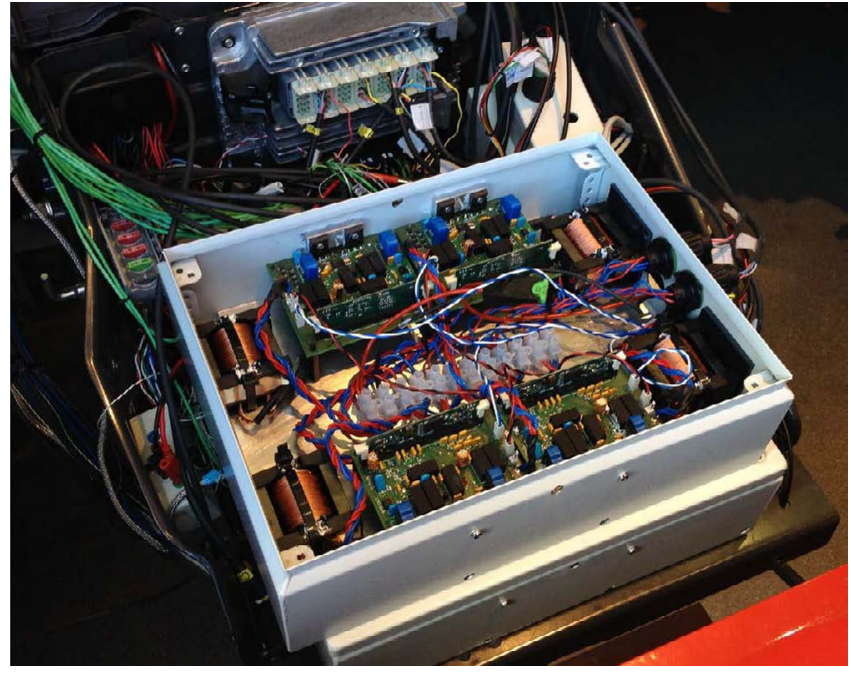

Figure 19. DC/DC converter connected to the TEG and the vehicle battery Condition of the DC/DC and data as voltage, current and PWM signals was transmitted to the main ECU of the vehicle via CAN-bus.

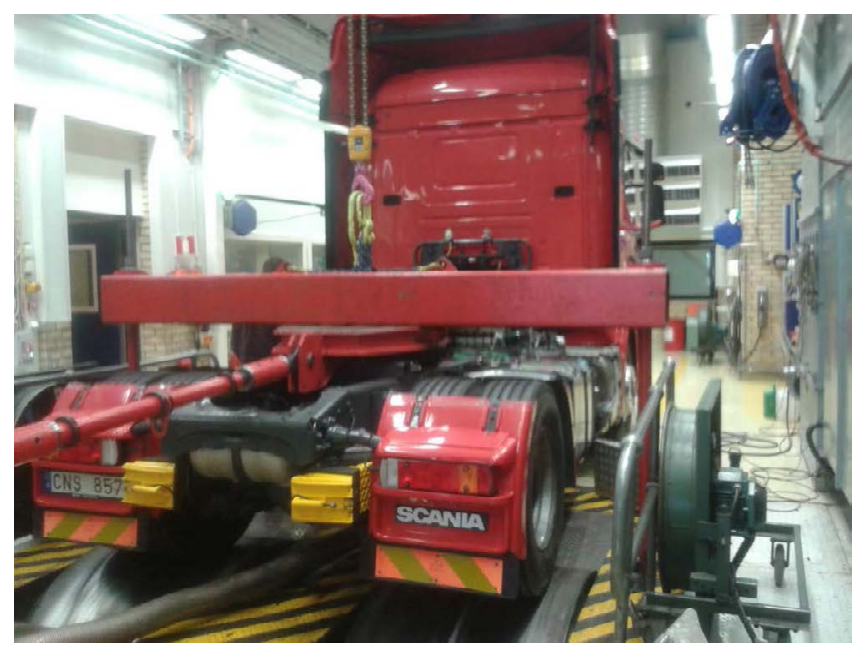

Figure 20. Truck equipped with the TEGs during the tests in the dyno-cell.

Table V

THE TOTAL GROSS OUTPUT POWER FROM ATS- AND EGR-TEG MEASURED BY EACH SUB-CONVERTER AND SENT TO THE VEHICLES MAIN ECU VIA CAN BUS.

\begin{tabular}{|l|c|c|c|c|c|c|c|c|c|}
\hline LHC & 1 & 2 & 3 & 4 & 5 & 6 & 7 & 8 & 9 \\
\hline $\begin{array}{l}\text { EGR-TEG } \\
{[\mathrm{W}]}\end{array}$ & 92 & 245 & 337 & 149 & 418 & 137 & 262 & 382 & 403 \\
\hline $\begin{array}{l}\text { ATS-TEG } \\
{[\mathrm{W}]}\end{array}$ & 245 & 385 & 490 & 300 & 440 & 205 & 340 & 410 & 420 \\
\hline
\end{tabular}

Moreover, in order to determine the dynamic behavior of the system, some transient measurements, by means of jumping from one LHC to another were performed. As seen in Fig. 21 the response time of the electrical system to the changes in LHC is rapid. However, the large mass of the thermal system, including the HXs, TEMs and cables in the EGR-TEG may need more than $200 \mathrm{~s}$ to reach the steady-state condition of the actual LHC. In fact, that time is very short in the context of LHC where the vehicle is running at LHC-6 during $40 \%$ of the driving time, and at LHC-4 and 7 together during $37 \%$ of the driving time. Due to the large gas mass flow in the ATS, the response time of the ATS-TEG is faster than for the EGR-TEG.

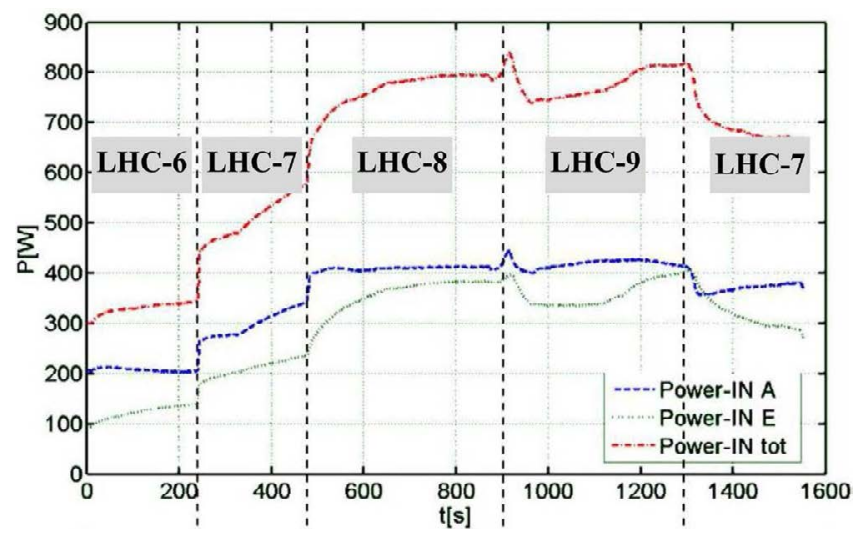

Figure 21. Results from the transient measurements showing the output power from the ATS-TEG and EGR-TEG. The ICE of HDV runs first from LHC-4 ( $\mathrm{t}=0$ ) to LHC-6 and continues to LHC-7, 8, 9 and back to LHC-7. The horizontal dashed lines represents the times the condition of the ICE changes from one LHC to another.

\section{CONCLUSION}

This paper presents the electrical design of a prototype thermoelectric waste-heat recovery system for a real-scale and drivable heavy duty vehicle. The electrical system design in a thermoelectric generator includes the connection configuration of thermoelectric modules, power converter topology and maximum power point tracker algorithm. The electrical system is subdivided into two sub-systems: one ATS sub-system with 224 TEMs and one EGR sub-system with 240 TEMs. Each of these sub-systems is connected to the vehicle battery through a four-channel interleaved DC/DC converter. Experimental results showing the gross power recovered by the TEG from the HDV are presented. The maximum recovered electrical power is approximately one kilowatt, and the converter efficiency is 98 percent. The proposed power converter contains a minimum number of passive components keeping the power losses, cost, weight and complexity of the system at a level the automotive industry expects for a full-scale drivable vehicle. Furthermore, efficiency measurements were performed on the power converter with two different semiconductor devices. Usually, SiC MOSFETs are used as a replacement for Si IGBTs in high-voltage/power applications. Experiments showed that SiC MOSFETs can be beneficial to use as a substitute for Si MOSFETs also in low-voltage applications. Moreover, it was shown that in a TEG with a large number of TEMs, it is extremely important to connect the TEMs in a way that high voltage and high internal resistance is obtained from a string of modules. This can be achieved by connecting a sufficient number of thermoelectric modules in series. The large value of the internal resistance enables to track and extract the maximum available power from the thermoelectric generator. In addition, the series connection of the modules minimizes the risk of failure or loss of power due to mechanical mismatch between different 
modules, which increases the reliability of the system. In the setup, however, the modules are connected in strings with two parallel modules in pair and then in series with the next pair, in order to increase the reliability considering open-circuit faults. From a thermal point-of-view it is very important to realize that the thermal conductance and thermal capacity of both the heat source and the heat sink, are limited when designing the system. It should be noted that the ability of controlling thermal current, by adjusting the electrical current during extreme conditions, may be used to optimize the system for best performance. Due to the same reason, the electrical current needs to be kept at a low level to keep $\Delta T$ high during normal conditions. Additionally, in order to study the response time of the system, transient measurements were performed. The conditions of the ICE was changed from one LHC to another before the steady-state was reached and the TEGs' output power was studied. Since the gas mass flow is lower in the EGR the time to reach the steady-state, is larger in the EGR-TEG compared to the ATS-TEG. This behavior may be considered for the designing of TEGs in vehicles as for instance public buses, with a large number of start/stop or changes in driving conditions.

It is worth mentioning that the TEG will add losses to the system and affect the total efficiency of the ICE. The TEGs' gross power determines the specifications of the electrical system and the design of the power converters. The actual net power is affected by the hydraulic losses such as; added back-pressure into the exhaust system, increased temperature in the charge air cooler and in the low temperature radiators. Therefore, the thermodynamical system and the hydraulic losses, influencing the net power of the TEG is investigated and discussed in [16] and [45]. From the system perspective of view, the total generated net power costs approximately $150 \$$ per watt and the net-power-to-weight ratio of the complete system was calculated to $5 \mathrm{~W} / \mathrm{kg}$ for this prototype. Clearly, the cost of a TEG needs to decrease to 1-2 \$ per watt in series production to be profitable for automotive applications.

\section{ACKNOWLEDGMENT}

The authors would like to thank the pre research institution at Scania, Swedish Research (Swerea) IVF AB, Eberspeacher Exhaust Technology, and TitanX Powertrain Cooling. A Special thanks to MSc. Jan Dellrud and Dr. Ali Saramat at Scania, Dr. Olof Erlandsson and Dr. Arnaud Contet at TitanX, Dr. Klas Brinkfeldt at Swerea IVF, and Dr. Gerd Gaiser and Dr. Fabian Frobenius at Eberspeacher for their contributions in this project.

\section{REFERENCES}

[1] J. G. Haidar and J. I. Ghojel, "Waste heat recovery from the exhaust of low-power diesel engine using thermoelectric generators," in Thermoelectrics, Proceedings ICT. International Conference on, 2001, pp. 413-418.

[2] J. Thomas, "Drive cycle powertrain efficiencies and trends derived from EPA vehicle dynamometer results," SAE Int. J. Passeng. Cars - Mech. Syst., vol. 7, pp. 1374-1384, Oct. 2014.

[3] A. Killander and J. C. Bass, "A stove-top generator for cold areas," in Thermoelectrics, Fifteenth International Conference on, Mar. 1996, pp. 390-393.
[4] M. Ashraf and N. Masoumi, "A thermal energy harvesting power supply with an internal startup circuit for pacemakers," IEEE Trans. VLSI Syst., vol. 24, no. 1, pp. 26-37, Jan. 2016.

[5] C. Watkins, B. Shen, and R. Venkatasubramanian, "Low-grade-heat energy harvesting using superlattice thermoelectrics for applications in implantable medical devices and sensors," in 24th International Conference on Thermoelectrics (ICT)., Jun. 2005, pp. 265-267.

[6] G. J. Snyder, A. Borshchevsky, A. Zoltan, T. Caillat, J. P. Fleurial, B. Nesmith, J. Mondt, T. McBirney, D. Allen, J. C. Bass, S. Ghamaty, N. Elsner, and L. Anatychuk, "Testing of milliwatt power source components," in Thermoelectrics, Proceedings ICT '02. Twenty-First International Conference on, Aug. 2002, pp. 463-470.

[7] G. C. Christidis, I. C. Karatzaferis, M. Sautreuil, E. C. Tatakis, and N. P. Papanikolaou, "Modeling and analysis of an innovative waste heat recovery system for helicopters," in 15th European Conference on Power Electronics and Applications (EPE), 2013, pp. 1-10.

[8] F. Ritz and C. E. Peterson, "Multi-mission radioisotope thermoelectric generator (MMRTG) program overview," in IEEE Aerospace Conference Proceedings (IEEE Cat. No.04TH8720), vol. 5, Mar. 2004, p. 2957.

[9] J. Dongsheng and Z. Pei, "An electrical power system of mars rover," in IEEE Conference and Expo Transportation Electrification Asia-Pacific (ITEC Asia-Pacific), Aug. 2014, pp. 1-4.

[10] "Green Car Congress: GMZ Energy successfully demonstrates $1 \mathrm{~kW}$ thermoelectric generator for Bradley Fighting Vehicle," www.greencarcongress.com/2014/12/20141203-gmz.html, last accessed 2017-09-01.

[11] L. A. Fisk, "Journey into the unknown beyond," Science, vol. 309, no. 5743, pp. 2016-2017, 2005.

[12] M. M. M. Daud, N. B. M. Nor, and T. Ibrahim, "Novel hybrid photovoltaic and thermoelectric panel," in IEEE International Power Engineering and Optimization Conference Melaka, Malaysia, Jun. 2012, pp. $269-274$.

[13] D. Yang and H. Yin, "Energy conversion efficiency of a novel hybrid solar system for photovoltaic, thermoelectric, and heat utilization," IEEE Trans. Energy Convers., vol. 26, no. 2, pp. 662-670, Jun. 2011.

[14] L. Kütt and M. Lehtonen, "Automotive waste heat harvesting for electricity generation using thermoelectric systems 2014; an overview," in IEEE 5th International Conference on Power Engineering, Energy and Electrical Drives (POWERENG), May 2015, pp. 55-62.

[15] L. Heber, S. Vale, and H. E. Friedrich, "Preliminary investigations for a thermoelectric generator as an alternative energy converter for commercial vehicles," in 11th International Conference on Ecological Vehicles and Renewable Energies (EVER), 2016, pp. 1-8.

[16] A. E. Risseh, H. P. Nee, O. Erlandsson, K. Brinkfeldt, A. Contet, F. Frobenius, G. Gaiser, A. Saramat, T. Skare, S. Nee, and J. Dellrud, "Design of a thermoelectric generator for waste heat recovery application on a drivable heavy duty vehicle," SAE Int. J. Commer. Veh., vol. 10, pp. 26-44, Apr. 2017

[17] M. Srinivasan and S. M. Praslad, "Advanced thermoelectric energy recovery system in light duty and heavy duty vehicles: Analysis on technical and marketing challenges," in International Conference on Power Electronics and Drives Systems, vol. 2, 2005, pp. 977-982.

[18] Q. E. Hussain, D. R. Brigham, and C. W. Maranville, "Thermoelectric exhaust heat recovery for hybrid vehicles," SAE Int. J. Engines, vol. 2, pp. 1132-1142, Apr. 2009.

[19] I. Arsie, A. Cricchio, V. Marano, C. Pianese, M. D. Cesare, and W. Nesci, "Modeling analysis of waste heat recovery via thermo electric generators for fuel economy improvement and $\mathrm{CO} 2$ reduction in small diesel engines," SAE Int. J. Passeng. Cars Electron. Electr. Syst., vol. 7, pp. 246-255, Apr. 2014.

[20] D. M. Rowe, J. Smith, G. Thomas, and G. Min, "Weight penalty incurred in thermoelectric recovery of automobile exhaust heat," Journal of Electronic Materials, vol. 40, no. 5, p. 784, Mar. 2011.

[21] J. C. Bass, N. B. Elsner, and F. A. Leavitt, "Performance of the 1 $\mathrm{kW}$ thermoelectric generator for diesel engines," in AIP Conference Proceedings, vol. 316, no. 1, 1994, pp. 295-298.

[22] N. A. Zarkadis, C. G. Zogogianni, and E. C. Tatakis, "Investigation of the behaviour of a high step-up $\mathrm{dc} / \mathrm{dc}$ converter used in a waste heat recovery system for marine applications," in 18th European Conference on Power Electronics and Applications (ECCE Europe), Sep. 2016, pp. $1-10$.

[23] J. H. Carstens and C. Gühmann, "Adaptive control of a boost-buck converter for thermoelectric generators," in European Control Conference (ECC), Jun. 2014, pp. 2121-2126.

[24] R.-Y. Kim and J.-S. Lai, "Aggregated modeling and control of a boost-buck cascade converter for maximum power point tracking of a 
thermoelectric generator," in Twenty-Third Annual IEEE Applied Power Electronics Conference and Exposition, 2008, pp. 1754-1760.

[25] X. Zhang, K. T. Chau, C. C. Chan, and S. Gao, "An automotive thermoelectric-photovoltaic hybrid energy system," in IEEE Vehicle Power and Propulsion Conference, Sep. 2010, pp. 1-5.

[26] C. Goupil, W. Seifert, K. Zabrocki, E. Müller, and G. J. Snyder, "Thermodynamics of thermoelectric phenomena and applications," Entropy, vol. 13, no. 8, pp. 1481-1517, 2011.

[27] G. J. Snyder and E. S. Toberer, "Complex thermoelectric materials," Nat. Mater, vol. 7, no. 2, pp. 105-114, Feb. 2008.

[28] D. Pollock, "CRC Handbook of Thermoelectrics", 1st ed. CRC Press LLC, 1995, ch. 2, Thermoelectric Phenomena.

[29] D. Emin, "Thermoelectrics Handbook, Macro to Nano", 1st ed. CRC Press Inc, 2006, ch. 5, Effects of Charge Carriers Interactions on Seebeck Coefficients

[30] F. J. DiSalvo, "Thermoelectric cooling and power generation," Science, vol. 285 , no. 5428 , pp. 703-706, 1999 .

[31] M. Freunek, M. Müller, T. Ungan, W. Walker, and L. M. Reindl, "New physical model for thermoelectric generators," Journal of Electronic Materials, vol. 38, no. 7, pp. 1214-1220, 2009.

[32] A. E. Risseh and H. P. Nee, "High-efficiency step-down converter for on-board thermoelectric generators on heavy duty vehicles," in 9th International Conference on Power Electronics and ECCE Asia (ICPE), Jun. 2015, pp. 869-873.

[33] Y. Apertet, H. Ouerdane, O. Glavatskaya, C. Goupil, and P. Lecoeur, "Optimal working conditions for thermoelectric generators with realistic thermal coupling," EPL (Europhysics Letters), vol. 97, no. 2, p. 28001, 2012.

[34] A. Vargas-Almeida, M. A. Olivares-Robles, and P. Camacho-Medina, "Thermoelectric system in different thermal and electrical configurations: Its impact in the figure of merit," Entropy, vol. 15, no. 6 , p. 2162,2013

[35] Y. Apertet, H. Ouerdane, C. Goupil, and P. Lecoeur, "From local force-flux relationships to internal dissipations and their impact on heat engine performance: The illustrative case of a thermoelectric generator," Phys. Rev. E, vol. 88, p. 022137, Aug. 2013.

[36] G. Min, "Improving the conversion efficiency of thermoelectric generators through 'pulse mode' operation," in AIP Conference Proceedings, vol. 1449, no. 1, 2012, pp. 447-449.

[37] A. Montecucco, J. Siviter, and A. R. Knox, "The effect of temperature mismatch on thermoelectric generators electrically connected in series and parallel," Applied Energy, vol. 123, pp. 47 - 54, 2014.

[38] A. E. Risseh and H. P. Nee, "Design of high-efficient converter for on-board thermoelectric generator," in IEEE Conference and Expo Transportation Electrification Asia-Pacific (ITEC), Aug. 2014, pp. 1-6.

[39] J. Eakburanawat and I. Boonyaroonate, "Development of a thermoelectric battery-charger with microcontroller-based maximum power point tracking technique," Applied Energy, vol. 83, no. 7, pp. 687-704, 2006.

[40] R. Y. Kim and J. S. Lai, "A seamless mode transfer maximum power point tracking controller for thermoelectric generator applications," IEEE Trans. Power Electron., vol. 23, no. 5, pp. 2310-2318, Sep. 2008.

[41] C. Duan, H. Bai, W. Guo, and Z. Nie, "Design of a 2.5-kW 400/12-V high-efficiency DC/DC converter using a novel synchronous rectification control for electric vehicles," IEEE Trans. Transp. Electrif., vol. 1, no. 1, pp. 106-114, Jun. 2015.

[42] A. E. Risseh, H.-P. Nee, and K. Kostov, "Fast switching planar power module with $\mathrm{SiC}$ MOSFETs and ultra-low parasitic inductance," in The 2018 International Power Electronics Conference -ECCE Asia(IPEC-Niigata), May 2018, pp. 12 - 17.

[43] A. E. Risseh, H. P. Nee, and K. Kostov, "Realization of a planar power circuit with silicon carbide MOSFETs on printed circuit board," in 24th International Symposium on Power Electronics, Electrical Drives, Automation and Motion - (SPEEDAM 2018), Jun. 2018.

[44] T. Esram and P. L. Chapman, "Comparison of photovoltaic array maximum power point tracking techniques," IEEE Trans. Energy Conv., vol. 22, no. 2, pp. 439-449, Jun. 2007.

[45] F. Frobenius, G. Gaiser, U. Rusche, and B. Weller, "Thermoelectric generators for the integration into automotive exhaust systems for passenger cars and commercial vehicles," Journal of Electronic Materials, pp. 1-8, 2015

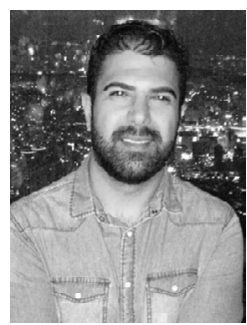

Arash Edvin Risseh (S'11) received M.Sc degree in physics and electrical engineering from Lulea University of Technology, Sweden, in 2010. He is currently working toward the Ph.D. degree in the Department of Electric Power and Energy Systems at KTH, Royal Institute of Technology, Stockholm, Sweden. His main research interests include gate-diver design and power converters with $\mathrm{SiC}$ devices with an extra interest in power conditioning system for renewable energy sources.

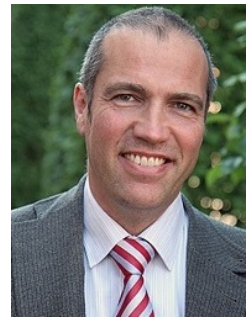

Hans-Peter Nee (S'91-M'96-SM'04-F'17) was born in Västeras, Sweden, in 1963. He received the M.Sc., Licentiate, and Ph.D. degrees from KTH Royal Institute of Technology, Stockholm, Sweden, in 1987, 1992, and 1996, respectively, all in electrical engineering. Since 1999, he has been a Professor of power electronics in the Department of Electric Power and Energy Systems, KTH. His research interests include power electronic converters, semiconductor components, and control aspects of utility applications, such as FACTS and high-voltage direct-current transmission, and variable-speed drives. Professor Nee was a Member of the Board of the IEEE Sweden Section for many years and was the Chair of the Board from 2002 to 2003. He is also a Member of the European Power Electronics and Drives Association and is involved with its Executive Council and International Steering Committee.

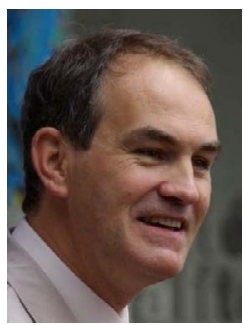

Christophe Goupil (M'17) is Professor of Condensed Matter and Electronics at Universitè Paris Diderot, where he teaches Solid State Physic, Thermodynamics, Electronics and Semi-Conductor Physics. After 8 years of development of thermoelectric applications into industrial programs including heat recovery in the Automotive and Aeronautical domains, and heat management in buildings, Professor Goupil is now in charge of the DyCo (www.dyco.fr) research group. Using a non-equilibrium thermodynamic approach, his research focuses on the coupled dynamics of fluxes and potentials in classical and quantum systems. Professor Goupil develops interdisciplinary projects ranging from fundamental coupled transport in mesoscopic systems to the metabolisms of biological systems and Macroeconomic models. 